\title{
Comércio exterior brasileiro de acordo com a intensidade tecnológica dos setores industriais: notas sobre as décadas de 1990 e 2000
}

Brazilian foreign trade according to manufacturing industries' technological intensity: notes on the 1990s and 2000s

Tulio Chiarini

Ministério da Ciência, Tecnologia e Inovação

Ana Lucia Gonçalves da Silva

Universidade Estadual de Campinas

\section{Abstract}

The quality of the insertion of a country into foreign trade is an indirect way of assessing the degree of technological dependence of its industrial sectors and of qualifying the possibility of an effective transfer of technology through imports. Based on two premises, we seek to analyze the Brazilian foreign trade according to the technological intensity of the industrial sectors. The first is that importing technology can foster the rapid modernization of the importing nation and also serves as an indicator of lack of technological capability. The second is that the export of technology may indicate the technological capability of a nation. With the Brazilian data, it is verified that, from 1996 to 2010, there was a negative trade balance of "high technology industries", that is, Brazil is "debtor of goods with high technological density". In contrast, Brazil presented, during the same period, a positive balance in the trade of "low technology industries".

\section{Keywords}

international trade; international technology transfer; technological capability; economic development; Brazil.

JEL Codes O10; O14; F10.

\section{Resumo}

A qualidade da inserção de um país no comércio exterior é uma forma indireta de avaliar o grau de dependência tecnológica de seus setores industriais e de qualificar a possibilidade de efetiva transferência de tecnologia via importações. Com base em duas premissas, busca-se analisar o comércio exterior brasileiro de acordo com a intensidade tecnológica dos setores industriais. A primeira é que a importação de tecnologia pode auxiliar a rápida modernização da nação importadora e igualmente serve como indicador da inaptidão tecnológica. Já a segunda é que a exportação de tecnologia pode indicar a aptidão tecnológica dessa nação. Com os dados brasileiros, verifica-se que, de 1996 a 2010, houve saldo negativo de comércio de produtos da indústria de "alta intensidade tecnológica", ou seja, o Brasil é "devedor de produtos com elevada densidade tecnológica". Contrariamente, o país apresentou, no mesmo periodo, saldo positivo no comércio de produtos da indústria de "baixo conteúdo tecnológico".

\section{Palavras-chave}

comércio internacional; transferência internacional de tecnologia; aptidão tecnológica; desenvolvimento econômico; Brasil.

Códigos JEL O10; O14; F10. 


\section{Introdução}

Parte-se neste estudo de duas premissas: i) a importação de tecnologia, por um lado, pode auxiliar a rápida modernização da nação importadora e, por outro, pode indicar sua inaptidão tecnológica, portanto, seu grau de dependência tecnológica; ii) as exportações de tecnologia, por sua vez, podem indicar a aptidão tecnológica dessa nação.

Presume-se, assim, que existe a possibilidade de que haja transferência internacional de tecnologia pelo fluxo internacional de comércio (em particular, porque existem mercadorias com tecnologias corporificadas) e supõe-se também que o comércio internacional é fonte de aprendizado para as firmas domésticas a partir do relacionamento com usuários e fornecedores externos.

Quanto maior a exposição de uma nação às mercadorias que corporificam um dado estado da arte tecnológico, maiores as chances de ela "imitar" e aprender tal tecnologia (por meio de engenharia reversa, por exemplo) e modernizar seu setor industrial. No entanto, essa capacidade de "absorver" e "aprimorar" essas mercadorias e tecnologias depende de condições histórico-estruturais da nação importadora.

O grau de aptidão tecnológica do país importador é, por isso, um elemento que ajuda a configurar essas condições estruturais. Desse modo, a inaptidão tecnológica pode resultar em dependência tecnológica, a qual pode ser inferida pela elevada (e continuada) importação de produtos com maior densidade tecnológica, demonstrando a incapacidade doméstica de inovar.

Contrariamente, quanto maior a exportação de produtos de empresas com maior intensidade tecnológica, maior sua aptidão tecnológica para colocar produtos de elevado valor agregado no mercado internacional. Ademais, as exportações podem permitir um processo de aprendizado (importante para o processo inovativo da empresa exportadora), se envolver a interação com fontes de conhecimentos externos, tais como clientes, fornecedores de bens de capital, etc.

Nessa esteira, busca-se, com as premissas explicitadas, fazer uma análise empírica do caso brasileiro na última década do século XX e no alvorecer do século XXI, focando no fluxo de comércio internacional de mercadorias de acordo com a intensidade tecnológica dos setores industriais, isto é, setor de alta intensidade tecnológica, setor de média-alta intensidade 
tecnológica, setor de média-baixa intensidade tecnológica e setor de baixa intensidade tecnológica. A exploração desses dados é uma forma indireta de qualificar a transferência internacional de tecnologia e também de averiguar a aptidão tecnológica dos setores industriais e a dependência tecnológica brasileira.

Na primeira seção, são apresentadas as premissas do estudo. Na seção 2 , depois de introduzir a base de dados e a definição metodológica da "intensidade tecnológica" por setor industrial, faz-se um breve histórico do processo de desenvolvimento industrial brasileiro, nos itens 2.1 e 2.2 , tendo como objetivo recuperar algumas características que ajudam a entender os fluxos de comércio exterior brasileiro nos anos 1990 e 2000. Ainda na seção 2, no item 2.3, são explorados os dados do comércio exterior brasileiro segundo a intensidade tecnológica dos setores industriais. Por último, conclui-se este trabalho com alguns comentários finais.

\section{Comércio internacional de produtos com densidade tecnológica}

O comércio de mercadorias possibilita uma análise dupla, interessante, do ponto de vista macroeconômico. De um lado, mostra o padrão de inserção comercial de um país em âmbito internacional; de outro, exibe indiretamente o grau de aptidão tecnológica acumulada para lançar produtos nos mercados internacionais e o grau de dependência nacional em relação a produtos com elevado conteúdo tecnológico.

\subsection{A importação de produtos com densidade tecnológica}

A importação de tecnologias não produzidas domesticamente pode ser utilizada como um "atalho" para diminuir o hiato tecnológico ao permitir sua implementação no processo produtivo interno, de maneira relativamente mais rápida e menos custosa. Muito das tecnologias importadas não se adaptam às realidades locais e passam por adequações e melhorias incrementais servindo às condições específicas da nação importadora. Essa, porém, nem sempre é a regra. 
A nação importadora é apenas o locus de realização de um processo de inovação, cuja gestação lhe é inteiramente exógena, e, portanto, grande parte das externalidades geradas pelo processo inovativo não é por ela apropriada (Aurea; Galvão, 1998). Assim, o país importador não está envolvido diretamente na maior parte dos benefícios auferidos pelos inovadores (localizados nas nações exportadoras dessa tecnologia, onde foram gestadas), embora a importação de tecnologia possa resultar em relativa modernização do país.

Por isso, a despeito de alguns especialistas sugerirem que a importação de tecnologia per se não é relevante, pois não se trata de transferência de know-how, mas de show-how (Simon, 1991), em determinados contextos a importação de tecnologia contribuiu para o processo de aprendizado doméstico e para a redução do atraso relativo de algumas nações.

Exemplos históricos corroboram o fato de nações (periféricas ou não) utilizarem-se da importação de tecnologias (especialmente as da fronteira tecnológica) no esforço de modernizar sua base técnica (Aurea; Galvão, 1998). Há exemplos de nações retardatárias que conseguiram emparelhar com as relativamente mais avançadas (i.e., realizaram o catching-up), combinando a importação pesada de tecnologia com forte expansão dos esforços nativos dedicados à mudança técnica (Dosi; Freeman; Fabiani, 1994), como foi o caso da Coreia do Sul.

O ritmo de crescimento econômico de uma nação é fortemente condicionado pelo andamento de suas atividades inovativas endógenas (portanto, está vinculado à aptidão tecnológica acumulada), que, por sua vez, podem se beneficiar do fluxo de tecnologias e conhecimentos vindos do exterior. Assim sendo, sob certas circunstâncias, importação de tecnologia e esforços inovadores domésticos são atividades complementares (Katz, 1976; Freeman, 1987; James, 1988; Bell; Cassiolato, 1993; Dosi; Freeman; Fabiani, 1994; Hasenclever; Cassiolato, 1998; Radosevic, 1999; Freeman; Soete, 2008 [1974]).

A importação de tecnologia depende inversamente do "grau de desenvolvimento" da indústria do país importador. Desse modo, uma nação com os setores industriais de bens de consumo duráveis e de bens de capital consolidados tem sua pauta de importação de produtos por densidade tecnológica diferente daquela que possui apenas o primeiro setor. É possível, portanto, aquilatar o grau de dependência tecnológica de determinado país, com base na análise de sua pauta de importações. 


\subsection{A exportação de produtos com densidade tecnológica}

A exportação de tecnologia, por seu turno, pode ser utilizada como indicador de desempenho do desenvolvimento tecnológico e indiretamente da aptidão tecnológica do país exportador. Além do mais, o processo de exportação é importante para o aprendizado das empresas locais por meio do learn-by-exporting, já que as informações oferecidas pelos compradores estrangeiros - pela proximidade de relacionamento - são um dispositivo de focalização e consultoria com custo relativamente baixo para melhorar a capacidade de produção e a qualidade dos produtos produzidos endogenamente (Radosevic, 1999).

No momento de mudança de paradigma técnico-econômico, a nação líder pode exportar ampla gama de produtos e serviços novos (e melhorados) com características de rendimentos e custos superiores às dos seus competidores. Já as nações retardatárias, ainda presas a um padrão de produção relativamente obsoleto, tornam-se menos competitivas em termos de sua tecnologia, e suas exportações perdem cada vez mais espaço no mercado mundial (Freeman, 1987).

O hiato no design e na tecnologia faz com que os produtos sejam menos vendáveis, ou até mesmo invendáveis, em mercados externos, e o hiato no processo tecnológico impõe que os produtos sejam menos competitivos em termos de custos, de modo que se pode identificar interdependência entre processos de mudança técnica e desempenho econômico (produção e comércio) (Dosi; Freeman; Fabiani, 1994). Assim, a venda de tecnologias mostra a desenvoltura do país exportador no comércio mundial, seu conhecimento tecnológico acumulado e sua habilidade em criar outros produtos que serão absorvidos pelo mercado externo.

\section{0 caso brasileiro}

Nesta seção, apresentam-se alguns dados exploratórios do Brasil, nas décadas de 1990 e 2000, analisando a composição das importações e das exportações, segundo os setores industriais de acordo com sua intensidade tecnológica. Os dados de importação e exportação - dados esses secundários, disponibilizados por órgãos governamentais, como Banco Central do Brasil (BACEN) e Ministério do Desenvolvimento, Indústria e 
Comércio Exterior (MDIC); órgãos nacionais privados, como Fundação Centro de Estudos do Comércio Exterior (FUNCEX); e órgãos internacionais, como Organização para Cooperação e Desenvolvimento Econômico (OCDE) e Banco Mundial - fornecem indicadores que subsidiam a interpretação de fatos históricos e podem contribuir para avaliar o processo de transferência internacional de tecnologia no caso brasileiro, mesmo que indiretamente. As estatísticas por si sós não captam com exatidão a transferência de tecnologia, mas analisadas conjuntamente podem permitir reflexões e interpretações.

A classificação da Directorate for Science, Technology and Industry da OCDE das atividades industriais segundo a intensidade tecnológica utilizada na produção merece uma análise mais crítica, pois, valendo-se dela, é que a Secretaria de Comércio Exterior (SECEX) do MDIC segregou as exportações e as importações brasileiras. É exatamente dessa base de dados que o grosso das análises deste trabalho é feito.

A intensidade tecnológica refere-se ao nível de conhecimento incorporado aos produtos das empresas de cada setor industrial e é calculada, segundo a metodologia da OCDE (2003), levando em consideração o percentual de gasto em pesquisa e desenvolvimento $(\mathrm{P} \& \mathrm{D})$ sobre a produção. As atividades industriais são classificadas, portanto, em:

$i$. indústria de alta tecnologia: aeronáutica e aeroespacial; farmacêutica; material de escritório e informática; equipamentos de rádio, TV e comunicação; instrumentos médicos de ótica e precisão;

ii. indústria de média-alta tecnologia: máquinas e equipamentos elétricos; veículos automotores, reboques e semirreboques; produtos químicos (exclusive farmacêuticos); equipamentos para ferrovia e material de transporte;

iii. indústria de média-baixa tecnologia: construção e reparação naval; borracha e produtos plásticos; produtos de petróleo refinado e outros combustíveis; outros produtos minerais não metálicos; produtos metálicos;

iv. indústria de baixa tecnologia: produtos manufaturados e bens reciclados; madeira e seus produtos, papel e celulose; alimentos, bebidas e tabaco; têxtil, couro e calçados.

A tipologia proposta pela OCDE (2003) apresenta limitações, visto que é feita a partir de agregação de atividades manufatureiras industriais de acordo com a intensidade da tecnologia supostamente utilizada para lançar ao mercado produtos, não levando em consideração, por conseguinte, o grau de inovação de cada atividade industrial. Parte-se da premissa 
de que as empresas intensivas em tecnologia são mais inovadoras e mais eficientes, o que pode não ser o caso se análises desagregadas forem feitas. Por isso, seria perfeitamente factível identificar empresas classificadas como da indústria de alto conteúdo tecnológico não inovadoras e, inversamente, empresas inovadoras da indústria de baixo conteúdo tecnológico. Ademais, embora investimentos em $\mathrm{P} \& \mathrm{D}$ sejam importantes para atividades de alto conteúdo tecnológico, não são necessariamente relevantes para as demais atividades industriais.

De acordo com Hatzichronoglou (1997) e Zawislak, Fracasso e Tello-Gamarra (2013), outros fatores (tais como pessoal técnico-científico, tecnologia adquirida por meio de patentes, licenças e know-how, cooperação e relacionamento com outras empresas) desempenham papel relevante na avaliação da intensidade tecnológica das empresas industriais. Para Furtado e Carvalho (2005), a classificação proposta pela OCDE (2003) deve ser vista com cautela para países de inserção periférica no capitalismo internacional, como é o caso brasileiro, em razão da própria construção histórico-estrutural da indústria nesses países, já que atividades de alta densidade tecnológica foram construídas apenas com bases produtivas, sem desenvolvimentos de tecnologias e produtos.

Os problemas identificados na classificação da OCDE (2003) não invalidam a relevância da análise feita a seguir para a situação brasileira. Essa classificação propõe interpretações frutíferas e chama a atenção para a falta de aptidão tecnológica do setor industrial do país, especialmente daquelas indústrias com maior conteúdo tecnológico.

\subsection{Antecedentes: breves comentários}

O motor do crescimento econômico do Brasil no período 1950-1980 foi a indústria, a qual era relativamente diversificada e integrada. Impulsionada pelo mercado doméstico, possibilitou relativa convergência da estrutura produtiva brasileira vis-à-vis as economias mais maduras (com a crescente participação dos complexos metalmecânico e químico - característicos da Segunda Revolução Industrial). Entretanto, não se verificou a efetiva internalização de capacidades inovativas (Sarti et al., 2010).

A trajetória de industrialização por substituição de importações (ISI) usou o potencial de crescimento do mercado interno, e pouca ênfase foi 
dada à capacidade de competir globalmente. ${ }^{1} \mathrm{O}$ foco nas exportações quase sempre foi de natureza emergencial para sanar problemas no balanço de pagamentos (Pacheco; Almeida, 2013). Tal ênfase "cristalizou-se" na cultura industrial brasileira, de modo que, até hoje, a inserção internacional da indústria nacional é frágil.

Desde os anos 1950, as importações brasileiras de tecnologia estavam tipicamente desconexas das atividades inovativas significantes nas firmas que as importavam (Bell; Cassiolato, 1993). Os esforços de tecnologia não estavam direcionados para a fronteira tecnológica, mas para ajustar algumas tecnologias às condições locais (Radosevic, 1999). Desse modo, como consequência, as tecnologias importadas tinham pouco alcance no processo de assimilação no contexto de rápida mudança tecnológica.

Muitas vezes, as novas tecnologias adquiridas do exterior foram seguidas por certo grau de melhoramento na eficiência do processo e desempenho do produto, com adaptações relativamente menores e learn-by-doing e learn-by-using. A intensidade da mudança técnica incremental era com frequência inadequada para sustentar a competitividade internacional nos mercados tecnologicamente dinâmicos; portanto, não foram criadas outras bases de competitividade em atividades progressivamente de maior valor agregado (Bell; Cassiolato, 1993). No processo de ISI, o país adquiria licenças de fabricação de produtos ou de aplicação de processos novos, instruções de fabricação, indicações detalhadas sobre as máquinas e os equipamentos a utilizar e até mesmo o acesso a novos desenvolvimentos ou simples aperfeiçoamentos das técnicas e dos processos.

O que ocorreu foi que tais tentativas de transferir tecnologia, combinadas com a política de reserva de mercado pela qual foi efetuada a ISI (e a consequente falta de concorrência externa), deram lugar a uma aguda inér-

1 Isso se deve à própria natureza do processo de industrialização por substituição de importações, processo de desenvolvimento interno originário de restrições externas que se manifesta, primordialmente, pela ampliação e diversificação da capacidade produtiva industrial (Tavares, 1981). De acordo com Tavares (1981, p. 41), "a dinâmica do processo de desenvolvimento pela via de substituição de importações pode atribuir-se, em síntese, a uma série de respostas aos sucessivos desafios colocados pelo estrangulamento do setor externo, através dos quais a economia vai-se tornando quantitativamente menos dependente do exterior e mudando qualitativamente a natureza dessa dependência". O modelo ISI significou a criação de filiais isoladas que se submeteram a escalas e tecnologias consistentes com a existência de mercados fortemente protegidos e transações internacionais fortemente reguladas. A política vigente induziu em geral uma relação passiva dessas filiais com suas fontes de abastecimento de bens de capital, insumos e tecnologias e com pouca articulação com o setor empresarial doméstico (Vera-Vassallo, 1996). 
cia tecnológica, que levou as empresas domésticas a depender em excesso de acordos de licenças e de assistência técnica (síndrome da dependência tecnológica). Além do mais, a falta de concorrência externa gerou pouca "ânsia" por competir globalmente, o que implicou a desnecessidade de inovar constantemente, refletindo a baixa tradição inovadora das empresas.

Ademais, a insuficiente atenção ao desenvolvimento de esforços para dominar efetivamente os princípios básicos de engenharia de processos e de engenharia mecânica em que se assentavam as inovações da época, tendo em vista a modificá-las e melhor adaptá-las aos usos locais (Figueiredo, 1972), também ajudou a moldar o sistema nacional de inovação ${ }^{2}$ brasileiro, reconhecido como imaturo (Albuquerque, 1999). ${ }^{3}$

Cabe ressaltar que, no período de ISI, não houve formulação estratégica com implementação de uma política clara que buscasse deliberadamente a absorção social do conhecimento produtivo, com o conseguinte processo de aprendizagem industrial e tecnológica, o que comprometeu, no longo prazo, uma inserção internacional mais dinâmica e de qualidade superior (Vera-Vassallo, 1996).

Foi dada ênfase ao papel das empresas estatais e dos laboratórios de pesquisa públicos, enquanto ao setor privado doméstico não foi dada sig-

2 Por ser um conceito difuso e fluído, é possível encontrar diversas definições de Sistema de Inovação (SI). Uma é aquela que o caracteriza como um arranjo institucional que envolve diversos elementos constituintes que interagem e se articulam entre si, quais sejam: (1) firmas, com seus laboratórios de pesquisa e desenvolvimento $(\mathrm{P} \& \mathrm{D})$ e suas redes de cooperação e interação; (2) universidades e institutos de pesquisa; (3) instituições de ensino; (4) sistema financeiro capaz de apoiar o investimento inovativo; (5) sistemas legais; (6) mecanismos mercantis e não mercantis de seleção; (7) governos; e (8) mecanismos e instituições de coordenação (Lundvall, 1988; 1992; Nelson, 1993; Freeman, 1995). Tendo esses elementos em mente, podem-se aplicá-los valendo-se de duas abordagens distintas (mas complementares) para auxiliar o entendimento da dinâmica inovativa e de desenvolvimento de certa nação. Uma, de caráter mais restrito, iguala inovação à ciência e tecnologia $(C \& T)$ e utiliza indicadores de especialização e desempenho relacionados à inovação, ou seja, esforços em $\mathrm{P} \& \mathrm{D}$ e C\&T. Os principais indicadores propostos nessa abordagem são gastos em $\mathrm{P} \& \mathrm{D}$, gastos em C\&T, gastos em educação superior, alocação de recursos humanos em P\&D e C\&T, patentes, publicações científicas, etc., e são componentes tangíveis da produção de conhecimento e aprendizado. No entanto, alguns elementos e relações do SI que afetam diretamente a capacidade de aprendizado são informais e difíceis de ser mensurados, razões pelas quais a abordagem do SI, deste ponto de vista, é ampla e inclui instituições sociais, infraestrutura de comunicação e educação, tipo de relação entre os agentes, etc. (Lundvall et al., 2009).

3 Albuquerque (1999) sugere uma tipologia que diferencia os Sistemas Nacionais de Inovação (SNIs) de acordo com o seu nível de desenvolvimento: SNIs "maduros" nos países desenvolvidos; SNIs "imaturos" em países em um nível intermediário de desenvolvimento, como os latino-americanos, a África do Sul e a Índia; e SNIs "inexistentes ou rudimentares" nos países menos desenvolvidos. Uma peculiaridade dos SNIs imaturos, como o brasileiro, é a existência de "conexões parciais" entre a infraestrutura científica e as atividades tecnológicas (Albuquerque, 1999, 2003). 
nificância no processo inovativo, e seus esforços se limitavam à adaptação de produtos e processos e dependiam da importação de máquinas e equipamentos ou de "efeitos de transbordamento" das empresas estatais ou das transnacionais (Katz, 2000).

O enfoque "desarrollo hacia adentro", apoiado no processo de ISI, já mostrara seu desgaste em meados dos anos 1970 e foi completamente abandonado em meados da década de 1980, quando o Brasil sofreu forte contração na demanda agregada e profundas transformações estruturais. Estas resultaram mais das circunstâncias macroeconômicas do que de uma evidente concepção errônea da estratégia de industrialização (Katz, 2005).

O baixo desempenho inovativo no período de ISI deveu-se, dentre outros fatores, à excessiva importância imputada ao capital estrangeiro (ao qual era atribuído o papel de ampliar a capacidade tecnológica do país mediante inovações de produto e processo trazidas pelas empresas transnacionais) e ao baixo interesse do setor público em transferir os resultados de atividades de pesquisa e desenvolvimento $(\mathrm{P} \& \mathrm{D})$ ao setor privado (Katz, 2000). Portanto, a ênfase concedida à importação de tecnologia em detrimento do seu desenvolvimento local (com a expectativa de que o crescimento da participação das transnacionais resultaria em transferências de tecnologias) fracassou como política tecnológica (Erber, 2000).

Chega-se aos anos 1980 com a crise da dívida externa e com problemas inflacionários. O foco das preocupações durante toda essa década está, grosso modo, na estabilização monetária. O parque industrial brasileiro ressente-se de pouca modernização e reduzidos investimentos, iniciando a década de 1990 com o mesmo perfil herdado dos anos 1970, quando havia praticamente completado a estrutura industrial típica da Segunda Revolução Industrial (Muniz, 2000), sendo esse o principal legado do período de ISI (Vera-Vassallo, 1996). Uma indústria que não investe, porém, torna-se progressivamente obsoleta, não cresce e tem dificuldade de assimilar progresso técnico; portanto, perde produtividade, novas oportunidades e competitividade (Cano, 2012). Foi exatamente o que aconteceu com a indústria nacional.

Tal situação assume caráter crítico quando se considera que o parque industrial brasileiro pouco se modernizou em um período em que o mundo exibe aceleração notável em termos de desenvolvimento tecnológico. Como resultado, características do período da ISI foram "cristalizadas", como a falta de diálogo entre a pesquisa pública e o setor produtivo pri- 
vado. Desse modo, o período pode ser evidenciado por equipamentos e bens de capital antiquados, métodos de produção obsoletos e modalidades deficientes de gestão e organização empresarial se comparados às nações centrais, além de fraca relação entre empresas e universidades/institutos públicos de pesquisa.

Dados o esgotamento do modelo de ISI e a crise da década de 1980, não somente o Brasil, mas outros países latino-americanos foram induzidos a um suposto "projeto de desenvolvimento", de inspiração neoliberal, apoiado na diminuição do Estado e na desregulamentação econômica, atribuindo ao mercado o papel de condutor do "desenvolvimento nacional". A década de 1990 marca, assim, uma ruptura no modelo de desenvolvimento brasileiro (Coutinho; Belluzzo, 1996).

Os reformistas liberais brasileiros apoiaram a estratégia de liberalização geral e irrestrita baseando-se nos seguintes pontos (Belluzzo, 2012b):

i. A estabilidade de preços criaria as condições para o cálculo econômico de longo prazo, estimulando o investimento privado;

ii. A abertura comercial disciplinaria os produtores domésticos, forçando-os a se tornarem mais competitivos;

iii. As privatizações e o IDE removeriam os gargalos de oferta na indústria e na infraestrutura;

iv. A liberalização cambial atrairia poupança externa em escala suficiente para complementar os esforços de investimento doméstico.

\subsection{As décadas de 1990 e 2000}

Do ponto de vista histórico-concreto, o processo de liberalização e as políticas de estabilização da economia brasileira nos anos 1990, sobretudo a valorização do câmbio, resultaram no barateamento das importações e afetaram a competitividade das exportações brasileiras. De acordo com Carneiro (2002), esse cenário macroeconômico determinou transformações na estrutura produtiva e na inserção externa brasileira.

Ao se aceitar a tendência de se adotar hábitos e consumo de economias mais desenvolvidas, ${ }^{4}$ emerge uma demanda "especializada" em bens 
e serviços cada vez mais sofisticados e de alto conteúdo tecnológico. Sem a reação do sistema produtivo interno, tal demanda acaba sendo suprida por importações (se houver disponibilidade de divisas e o câmbio estiver desvalorizado, caso do Brasil nos últimos anos).

O aparecimento dessa demanda sofisticada pode estimular os setores industriais domésticos mais eficientes a promover um incremento em suas atividades (desde que haja um ambiente macroeconômico e arcabouço institucional propícios), o que não foi a situação do Brasil.

O excesso de demanda, confirmado pelo aumento do coeficiente de importação, foi também acompanhado pelo aumento do coeficiente de exportação (Figura 1), resultado do processo de liberalização comercial vivenciado nos anos 1990. De acordo com Hiratuka e Negri (2004), o grau de abertura da economia ampliou-se, tornando-a mais vulnerável às mudanças nos mercados globais. A Figura 1 testemunha tanto o aumento do coeficiente de exportação (X/PIB, ou seja, a relação entre exportação e produto interno bruto) quanto o coeficiente de penetração (M/PIB, isto é, a relação entre importação e produto interno bruto). ${ }^{5}$

Os anos 2000 são igualmente marcados pelo aumento do grau de abertura vis-à-vis a década anterior, sendo a média no período 2000-2010 de 0,21, contra 0,14 no período 1990-2000 (Figura 1). Esse desempenho foi conseguido pela manutenção das políticas macroeconômicas adotadas durante os anos 1990, mantendo a taxa de juros e o câmbio "fora do lugar", em um ambiente externo benévolo - termos de intercâmbio entre produtos primários e manufaturados a favor dos países com disponibilidade recursos naturais (Belluzzo, 2008).

passo entre a estrutura produtiva e a estrutura de consumo é capaz de explicar o subdesenvolvimento. Assim, os padrões de consumo no Brasil, que imitam os dos países mais desenvolvidos, implicam a importação de tecnologia estrangeira, desenhada para países onde o custo relativo da mão de obra é mais elevado, impossibilitando o desenvolvimento de tecnologias adequadas às condições nacionais (Prado, 2011).

5 Ao contrário do PIB, o fluxo de comércio é medido em valores brutos, e não em valores agregados. Esse método de análise pode esconder importantes características do comércio exterior e da verdadeira inserção internacional do país. Por exemplo, produtos com alto conteúdo tecnológico podem ser exportados por países em desenvolvimento, mas na verdade esses podem estar participando apenas das fases de montagem da produção (maquillas) que requerem qualificação relativamente mais baixa, utilizando peças e componentes de elevado conteúdo tecnológico importados dos países mais desenvolvidos. Assim, as peças e os componentes importados são contabilizados entre as exportações nas quais houve a montagem do produto (nos países em desenvolvimento, por exemplo). Por isso, a análise dos valores brutos pode indicar que esse país é grande ator no mercado mundial de produtos dinâmicos intensivos em tecnologia, enquanto na verdade é apenas um mero montador (Akyuz, 2005). 


\section{Figura 1 Grau de abertura comercial $(\mathrm{X}+\mathrm{M}) / \mathrm{PIB}$, coeficiente de exportação (X/PIB) e coeficiente de penetração (M/PIB), Brasil, 1990-2010}

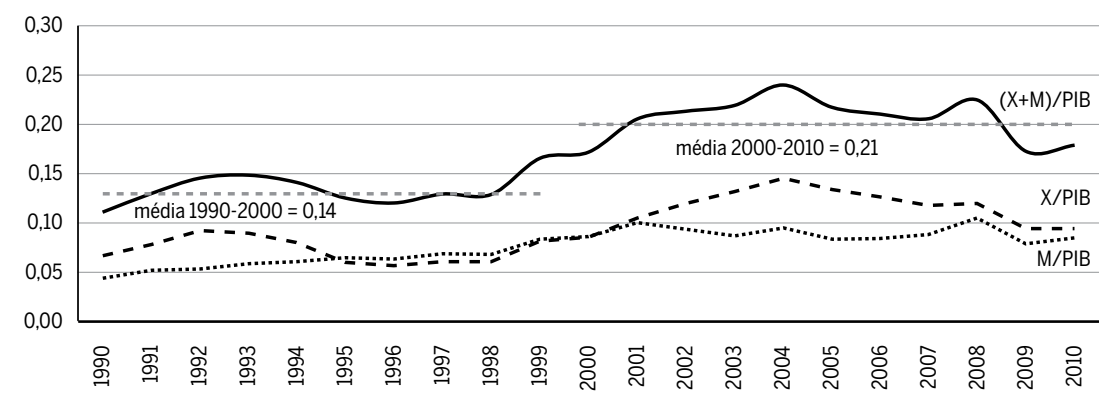

Fonte: Elaboração própria com base nos dados compilados pelo IPEAdata do Boletim Funcex de Comércio Exterior e do Boletim do Banco Central do Brasil (BCB Boletim/Ativ. EC.).

A despeito do aumento das mercadorias brasileiras exportadas - US\$ 31.414 milhões em 1990, US\$ 55.119 milhões em 2000 e US\$ 201.915 milhões em 2010 (Figura 2) -, a participação das mercadorias manufaturadas ${ }^{6}$ no total exportado registrou redução: em 1990 correspondia a 54,15\% do total exportado, enquanto em 2010 caiu para 39,40\% (Figura 2). Em 1990, do total exportado, $27,84 \%$ correspondiam à categoria de "produtos básicos" e essa participação cresceu para 44,58\% em 2010 (Figura 2), ou seja, um crescimento de 16,74 pontos percentuais nesse período.

A falta de modernização do parque industrial brasileiro foi identificada como resultante do excesso de proteção da indústria brasileira por tempo demasiado longo (como resultado da ISI). Portanto, o discurso público a partir da década de 1990 era de impor à indústria maior competição externa, o que resultaria em esforços para sua modernização. A abertura da economia possibilitou uma "enxurrada" de importações, e seu crescente

6 No acompanhamento das exportações brasileiras por grau de elaboração do produto, é possível classificá-las por fator agregado. Nesse conceito, as mercadorias são classificadas como "produto básico" ou "industrializado", sendo este último subdividido em "semimanufaturado" e "manufaturado". Os "produtos básicos" são as mercadorias que guardam suas características próximas ao estado em que são encontrados na natureza, isto é, possuem baixo grau de elaboração e baixo valor agregado, como as commodities agrícolas (café em grão, soja em grão, carne in natura, milho em grão, trigo em grão) e minerais. Já os "produtos industrializados" são aqueles que sofreram alguma transformação substantiva: os "semimanufaturados" ainda não estão em sua forma definitiva de uso, quer final, quer intermediário, uma vez que passarão por outro processo produtivo para se transformarem em "produto manufaturado" (por exemplo, a celulose é um produto semimanufaturado, ao passo que o papel é um produto manufaturado). 
volume colocou pressão sobre o market share e as margens de lucro dos produtos domésticos (Laplane; Sarti, 1997). A crescente importação "predatória" danificou a produção nacional e a ocupação da capacidade já instalada (Belluzzo, 2012b).

Figura 2 Distribuição das exportações por fator agregado, \% e total exportações, US\$ milhões, 1990-2010

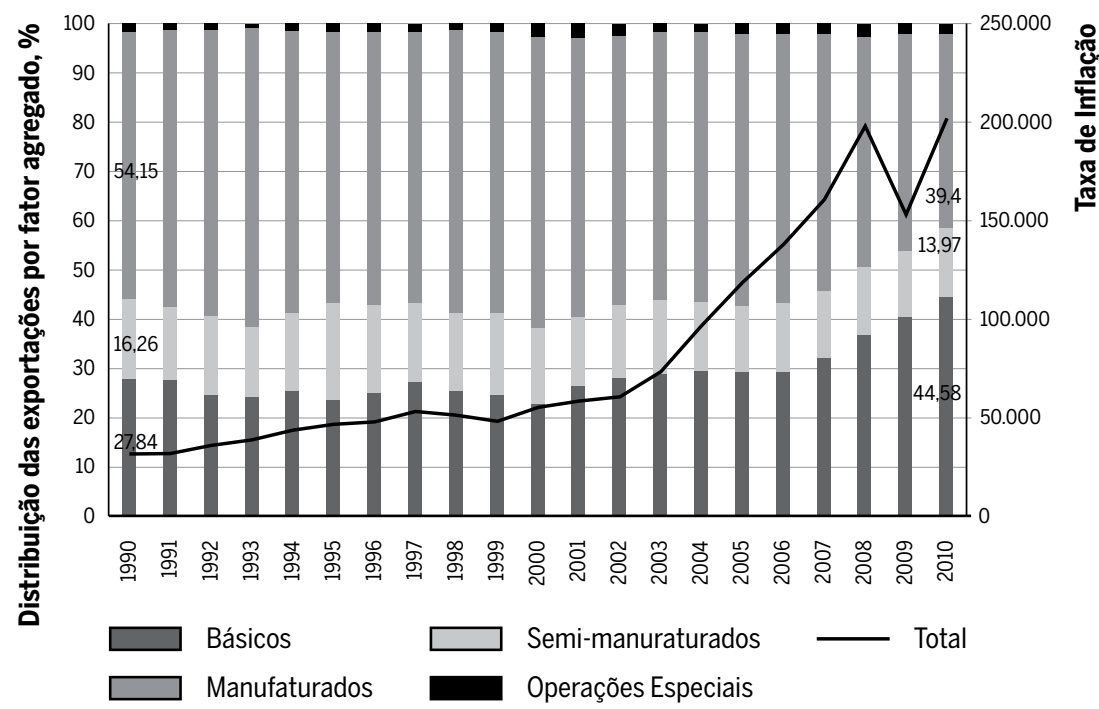

Fonte: Elaboração própria com base nos dados compilados pela SECEX/MDIC do Boletim do Banco Central do Brasil (BCB Boletim/Ativ. Ec.).

Nota: valor FOB.

Nesse contexto, a orientação do MCTI era que houvesse a extinção gradual do protecionismo destinado aos ramos de microcomputadores, microeletrônica e telecomunicações, e ao Estado caberia desenvolver e modernizar a infraestrutura tecnológica (metrologia, normalização técnica, certificação de conformidade, etc.) e reduzir seus grandes projetos de P\&D (Rangel, 1995).

Basicamente, as políticas industriais da década em questão se centraram no Programa Brasileiro da Qualidade e Produtividade (PBOP) e no Programa de Apoio à Capacitação Tecnológica da Indústria (PACTI) (Matesco; Hasenclever, 1998). Ademais, para incentivar maior participação do setor privado nos dispêndios em atividades inovativas, o governo propôs a concessão de incentivos fiscais de forma crescente ao longo dos anos 1990. 
A década de 1990 foi marcada por ações esparsas no que se refere à política de inovação, seguindo receituário neoliberal, com a ressalva da criação, pelo Ministério da Ciência, Tecnologia e Inovação (MCTI), dos Fundos Setoriais e também da proposta da Lei de Inovação (Koeller, 2007). Iniciou-se a articulação de uma proposta para a possível criação de uma política de inovação, cujo objetivo era propiciar estímulo às inovações tecnológicas por meio da modernização do ambiente regulatório, da integração do país na capacitação voltada para a inovação e da visão da Política de Ciência e Tecnologia como estratégica ao desenvolvimento (Chiarini; Rapini; Vieira, 2014).

A partir dos anos 2000, já no governo Lula, diferentes projetos de investimento foram efetuados, com orientação desenvolvimentista, envolvendo políticas de dinamismo do mercado interno, apoiando, assim, o setor privado e investimentos no setor de infraestrutura, políticas sociais e políticas de crédito. Além disso, passou-se a dar importância à inovação com maior amplitude. Houve a criação da Política Nacional de Ciência, Tecnologia e Inovação, e da Política Industrial, Tecnológica e de Comércio Exterior (PITCE). A PITCE preservou os objetivos definidos no período anterior, ou seja, a dinâmica da inovação e a difusão de tecnologias foram entendidas como facilitadores da disputa e da conquista de outros mercados, e, para tanto, políticas públicas foram equacionadas tendo como objetivo o aumento da eficiência econômica e do desenvolvimento e da difusão de tecnologias (Koeller, 2007).

Em maio de 2008, já no segundo mandato do governo Lula, um novo programa de promoção à indústria brasileira é lançado, com maiores pretensões em termos de abrangência, controles e metas, ampliando o número de setores e de instrumentos de apoio. Batizada de Política de Desenvolvimento Produtivo (PDP), a nova política visava à sustentação de um longo ciclo de desenvolvimento produtivo, apoiado em investimento, inovação, competitividade e exportações (Cano; Silva, 2010).

O Plano Brasil Maior (PBM), lançado em 2011 pelo governo Dilma Rousseff, continuou o planejamento econômico do governo Lula (PITCE e PDP), a fim de sustentar o crescimento econômico no Brasil, com foco em inovação e expansão industrial brasileira por meio de medidas como isenções para investimento produtivo e das exportações, expansão do crédito e melhoria regulamentar da inovação. O PBM confirma que o governo atribuía à indústria papel central na promoção do desenvolvimento do país, e 
suas forças estão ligadas ao pioneirismo de algumas ações como a redução de impostos sobre investimentos e exportações e a significativa contribuição da FINEP (Financiadora de Estudos e Projetos) e do BNDES (Banco Nacional de Desenvolvimento Econômico e Social) no financiamento ao investimento e à inovação (Almeida, 2011). No entanto, Almeida (2011, p. 12) nota que, mesmo com as medidas propostas pelo PBM, "o Brasil ainda está longe de ser um país facilitador e promotor do investimento à inovação e à exportação" e com essas medidas ainda é pouco provável que o país venha a se tornar mais autônomo em termos tecnológicos.

Os anos 2000, diferentemente da década de 1990 (com suas crises de liquidez internacional), contaram com um ambiente externo benévolo (com valorização dos preços das commodities e surto de liquidez externa), e as autoridades monetárias optaram por elevar os juros básicos ${ }^{7}$ e utilizar a valorização do real como instrumento de combate à inflação doméstica (Belluzzo, 2008). Para se ter uma ideia, durante o período 2000-2010, o câmbio foi cotado em média a R \$2,29/US\$ (segundo dados do Banco Mundial ${ }^{8}$ ). A valorização cambial, desde a estabilização pós-1994, propiciou o aumento das importações de insumos, peças e componentes do setor industrial e também incentivou os setores mais afetados pela concorrência asiática (sobretudo a chinesa) a importar bens finais e vendê-los domesticamente como se fossem produções nacionais (Belluzzo, 2008), enquanto serviu como desincentivo às exportações de produtos manufaturados brasileiros.

Valorizações excessivas no câmbio inibem a formação de expectativas favoráveis ao investimento produtivo (seja ele nacional, seja ele estrangeiro) voltado ao mercado externo ou destinado a concorrer com as importações; desse modo, a "incerteza cambial" compromete a capacidade exportadora da economia no longo prazo (Belluzzo, 2008).

Apesar de se reconhecerem os problemas conjunturais, as deficiências da base produtiva brasileira em termos de aptidão tecnológica ajudam a explicar o fraco desempenho exportador brasileiro da indústria de alta intensidade tecnológica, corroborado pelo baixo gasto em atividades de P\&D (Melo; Fucidji; Possas, 2015).

\footnotetext{
7 De acordo com dados do Banco Mundial, a taxa real de juros no período 2000-2010 foi, em média, 41,17\% a.a. Disponível em: <http://data.worldbank.org/indicator/FR.INR. RINR?cid=DEC_SS_WBGDataEmail_EXT>. Acesso em: 10/10/2014.

8 Taxa de câmbio oficial disponível em: <http://data.worldbank.org/indicator/PA.NUS. FCRF?cid=DEC_SS_WBGDataEmail_EXT>. Acesso em: 10/10/2014.
} 


\subsection{Comércio exterior dos setores industriais de acordo com a intensidade tecnológica}

Uma primeira inferência, no que se refere aos setores industriais classificados por intensidade tecnológica, ${ }^{9}$ é que a indústria de baixo conteúdo tecnológico correspondia a $43,02 \%$ das exportações brasileiras de produtos industriais em $1996,{ }^{10}$ enquanto apenas $5,11 \%$ eram de produtos de alto conteúdo tecnológico (Tabela A1, no Anexo). O primeiro grupo somava US\$ 17.175,98 milhões contra US\$2.041,73 milhões do último (Tabela A2, no Anexo). Contrariamente, $23,15 \%$ das importações de produtos industriais eram de produtos de alto conteúdo tecnológico em 1996 contra $15,65 \%$ de produtos de baixo conteúdo tecnológico, no mesmo período; em valores monetários, esse grupo correspondeu a US $\$ 7.045,73$ milhões, e aquele, a US\$10.421,98 milhões (Tabela A2, no Anexo).

Verifica-se, portanto, que houve saldo negativo no comércio de produtos da indústria de alto conteúdo tecnológico (US\$ 8.380,25 milhões) em 1996 e saldo positivo no comércio de produtos da indústria de baixo conteúdo tecnológico (US\$10.130,25 milhões) no mesmo ano, ou seja, o Brasil é "devedor de produtos de alto conteúdo tecnológico", em 1996.

O comportamento do comércio internacional dos setores industriais por intensidade tecnológica manteve o desempenho anteriormente apresentado no restante da década de 1990 e na década de 2000, ou melhor, o comércio externo de produtos da indústria de alto conteúdo tecnológico permaneceu deficitário e com tendência a aumentar o déficit a partir do início dos anos 2000, ao passo que o saldo do comércio de produtos da indústria de baixo conteúdo tecnológico manteve-se superavitário e com tendência a crescer a partir dos anos 2000 (Figura 3), figurando ainda com o perfil de "devedor de produtos de alto conteúdo tecnológico".

O "comércio de bens e serviços tecnológicos" (proxy para comércio de tecnologia) brasileiro traz consigo uma consequência indesejável, materializada sobretudo pelo permanente déficit na balança comercial de bens e serviços tecnológicos (Figuras 3 e 4). É possível sugerir que o aumento

9 Vide classificação apresentada na seção 2 .

10 A escolha do ano deveu-se simplesmente à disponibilidade de informações. A SECEX/ MDIC passou a utilizar a metodologia da OCDE para os dados de comércio exterior brasileiro, disponibilizando-os para os anos a partir de 1996. 
do déficit de produtos com alto conteúdo tecnológico, em parte, resulta da maior atividade interna demandante desses bens e, de outra parte, evidencia a perda de competitividade da indústria nacional em termos de produtos com alto conteúdo tecnológico.

Figura 3 Saldo comercial brasileiro dos setores industriais por intensidade tecnológica,

\section{US\$ milhões, 1996-2010}

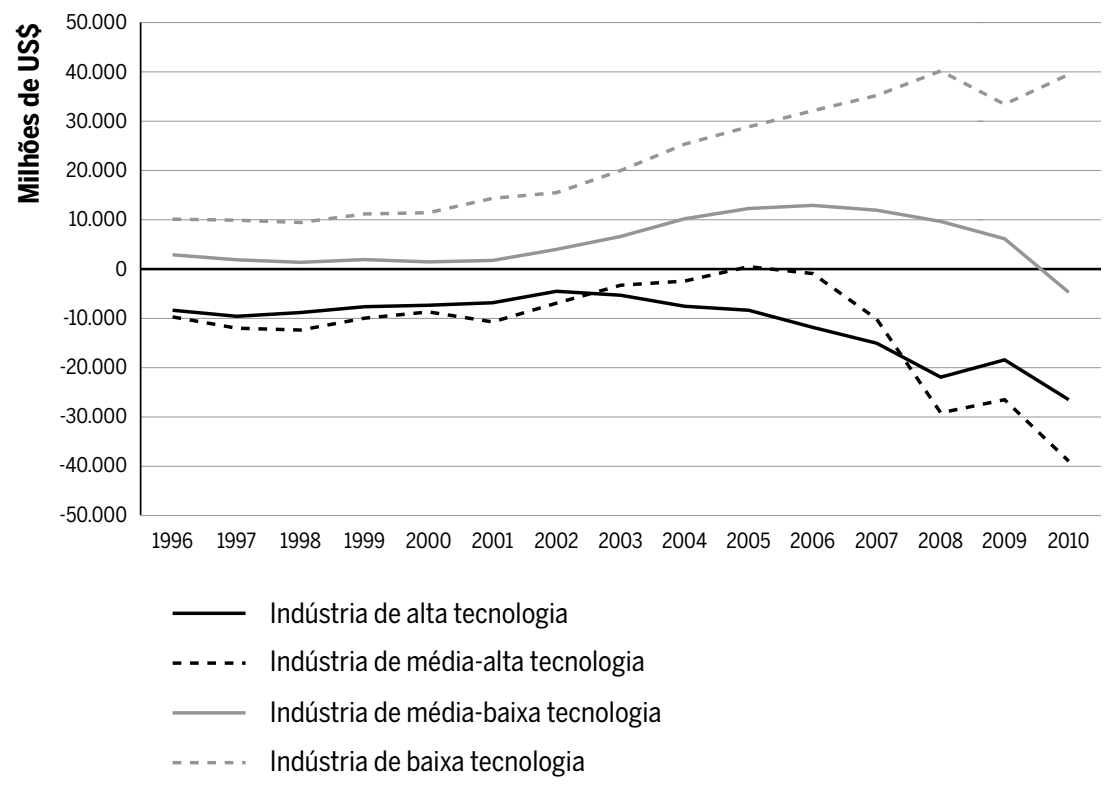

Fonte: Elaboração própria com base nos dados compilados pela SECEX/MDIC.

Nota: valor FOB. Classificação extraída de OECD, Directorate for Science, Technology and Industry, STAN Indicators, 2003.

A Figura 4 apresenta a taxa de comércio (X/M) dos setores industriais por intensidade tecnológica, para o período 1996-2010. Pode-se notar que a indústria de baixo conteúdo tecnológico gerou saldos correntes positivos e crescentes até meados de 2004, quando passou por um processo de queda, embora ainda gere saldos positivos. Vale lembrar que valores maiores do que a "unidade" indicam que, na operação corrente, são gerados saldos comerciais, e, contrariamente, valores menores do que a unidade indicam déficits. Os coeficientes de exportação (X/PIB) dos setores industriais por intensidade tecnológica são apresentados na Figura 5. 
Figura 4 Taxa de comércio (X/M) dos setores industriais por intensidade tecnológica, Brasil, 1996-2010

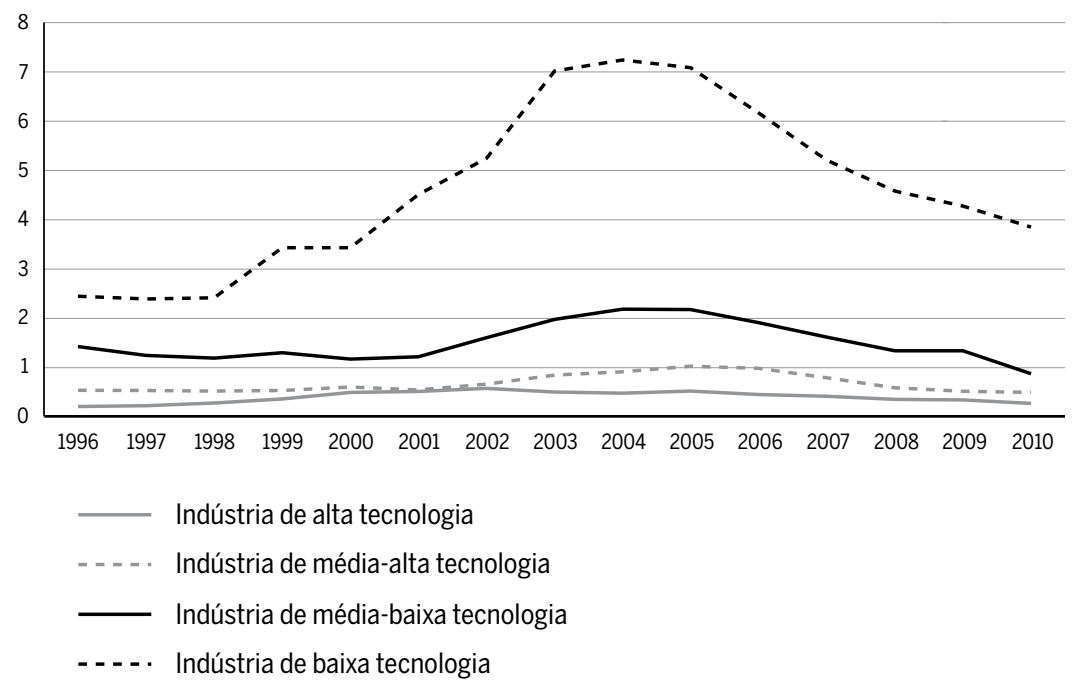

Fonte: Elaboração própria com base nos dados compilados pela SECEX/MDIC. Classificação extraída de OECD, Directorate for Science, Technology and Industry, STAN Indicators, 2003.

A perda de competitividade da indústria nacional verifica-se tanto pela queda da atividade econômica mundial em razão da crise financeira (no final dos anos 2000) quanto pelo processo de desindustrialização ${ }^{11}$ (iniciado na década de 1990), graças à ausência de adequadas políticas de desenvolvimento e da conjugação de juros elevados, falta de investimento, câmbio sobrevalorizado e exagerada abertura comercial (Cano, 2012).

11 A queda da participação da indústria de transformação no PIB de forma acentuada e constante é conhecida como "desindustrialização". De acordo com dados do IBGE (compilados pelo IPEAdata), em 1990, a indústria de transformação representava 26,54\% do PIB (preços de 2000), em 2000, representava 17,22\% e, em 2010,16,23\%. A indústria de transformação já chegou a representar em média 32,29\% do PIB, no período 1970-80. Há extenso debate sobre as causas e as consequências desse processo, porém é consenso que esse resultou em impactos profundos do ponto de vista da desarticulação e da desmobilização de elos importantes de algumas cadeias produtivas nacionais. Isso foi resultado e/ou resultou no aumento de importações de partes, peças e componentes da indústria brasileira. De acordo com Cano (2012), a desindustrialização no Brasil está ocorrendo como resultado de: i) política cambial instaurada a partir do Plano Real; ii) abertura desregrada da economia a partir de 1989; iii) taxa de juros elevada; iv) fluxo crescente do IDE. Hiratuka e Sarti (2015) recuperam as diferentes visões dentro do debate sobre a desindustrialização no Brasil e mostram que o conjunto de transformações concorrenciais, produtivas, tecnológicas e patrimoniais na economia global ajuda a entender o processo de desindustrialização. 
De acordo com Cano (2012), a política de câmbio excessivamente valorizado (utilizado como âncora de preços até os dias de hoje), conjugada com a prática de juros reais elevados (desincentivando o empresário capitalista a investir na economia industrial, cujo retorno esperado é relativamente contido quando comparado com a taxa de juros) e com a âncora fiscal, resulta na perda de competitividade internacional da indústria brasileira perante outros países.

Figura 5 Coeficiente de exportação (X/PIB) dos setores industriais por intensidade tecnológica, \%, Brasil, 1996-2010

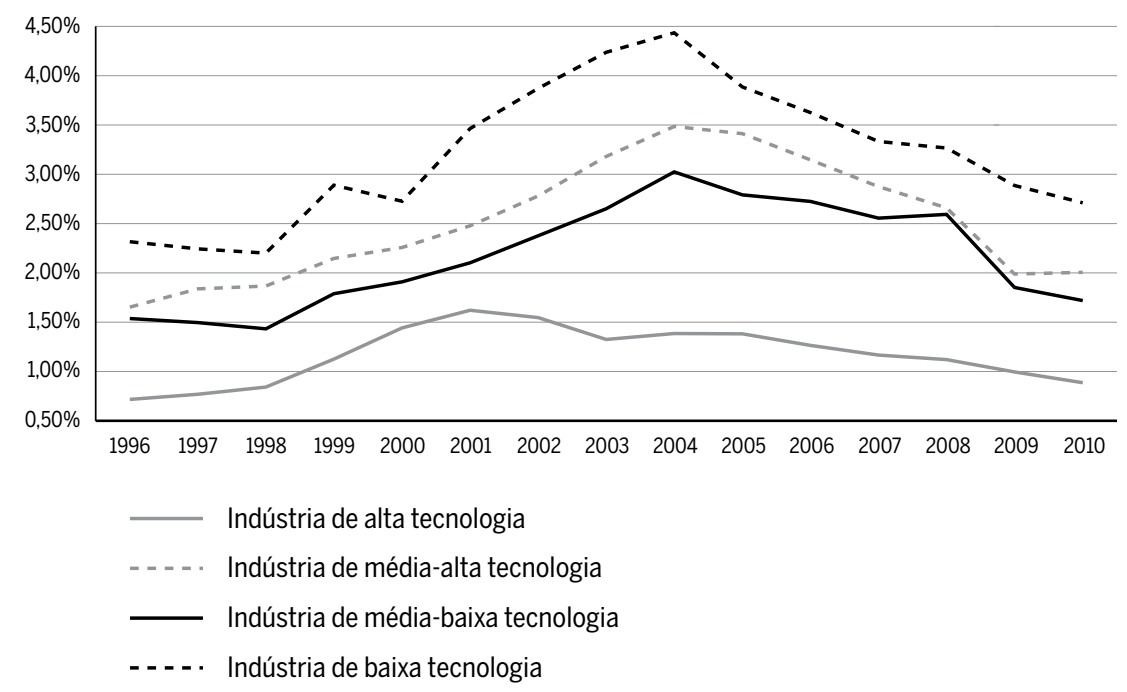

Fonte: Elaboração própria com base nos dados compilados pela SECEX/MDIC.

Nota: valor FOB. Classificação extraída de OECD, Directorate for Science, Technology and Industry, STAN Indicators, 2003.

Ademais, a abertura desregrada da economia brasileira nos anos 1990 (com a queda de tarifas e outros mecanismos protecionistas da indústria nacional) reduziu o grau de proteção diante da concorrência internacional (Cano, 2012). Um fator externo que merece destaque é a existência de barreiras significativas à entrada de linhas de produção intensivas em produtos de alto conteúdo tecnológico associada ao elevado conteúdo de $\mathrm{P} \& \mathrm{D}$ e aos significativos custos envolvidos na organização de cadeias produtivas. 
Além do mais, os mercados de produtos com alto conteúdo tecnológico são dominados por oligopolistas nos países industrializados que não competem no preço, mas com base em qualidade, design, marketing, marca e diferenciação de produtos. Desse modo, nesse caso, a participação nos mercados exportadores é muito mais concentrada do que no dos manufaturados exportados pelos países em desenvolvimento (Akyuz, 2005).

Voltando à analise de dados, a Figura 6 e a Figura 7 mostram as taxas de crescimento ano a ano tanto das exportações quanto das importações brasileiras dos setores industriais por intensidade tecnológica. A média de crescimento das exportações (Figura 6) da indústria de alta tecnologia no período $1997-2010$ foi de $8,55 \%$ ao ano, enquanto, no mesmo período, as médias de crescimento da indústria de média-alta tecnologia, média-baixa tecnologia e baixa tecnologia foram, respectivamente, de 6,54\% a.a., $5,72 \%$ a.a. e $7,20 \%$ a.a. $\bigcirc$ que chama a atenção é que, no período 2008-2010, ou seja, no período da crise financeira internacional, as taxas de crescimento dos referidos setores industriais foram: $-4,43 \%,-4,48 \%$, $-7,53 \%$ e $5,22 \%$ ao ano. Tais taxas tiveram redução de crescimento por causa da queda da atividade econômica mundial. No entanto, apesar da queda do setor de baixo conteúdo tecnológico, ele continuou crescendo.

\section{Figura 6 Taxa de crescimento (média móvel) das exportações brasileiras dos setores} industriais por intensidade tecnológica, 1996-2010

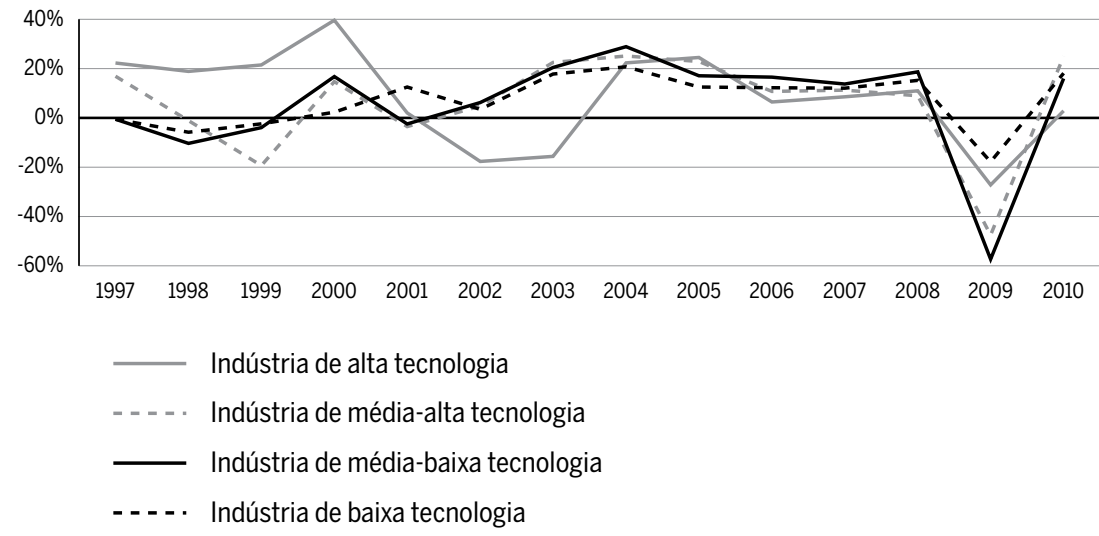

Fonte: Elaboração própria com base nos dados compilados pela SECEX/MDIC.

Nota: valor FOB. Classificação extraída de OECD, Directorate for Science, Technology and Industry, STAN Indicators, 2003. 
Por sua vez, as taxas de crescimento das importações (Figura 7) no período 1997-2010 foram as seguintes por tipo de indústria: de alto conteúdo tecnológico, 7,00\% a.a.; de médio-alto conteúdo tecnológico, 7,10\% a.a.; de médio-baixo conteúdo tecnológico, $7,41 \%$ a.a.; e de baixo conteúdo tecnológico, 2,72\%. No período 2008-10, as taxas de crescimento respectivas foram: 8,66\%, 10,78\%, 7,00\% e 13,97\% ao ano. Ou seja, o Brasil continuou com taxas crescentes de importação de maior densidade tecnológica mesmo no período da crise, o que pode corroborar a dependência de produtos com alto conteúdo tecnológico não produzidos domesticamente.

Apesar da ligeira melhora na participação da indústria de alto conteúdo tecnológico (que correspondia a 5,11\% em 1996 e chegou a 7,26\% em 2010) nas exportações brasileiras de produtos industriais, esse desempenho é ainda insatisfatório. Em quase 15 anos, a participação das exportações dos produtos de maior densidade tecnológica, que correspondia a $0,24 \%$ do PIB brasileiro em 1996, aumentou seu percentual para 0,43\% do PIB em 2010 (Tabela A2, no Anexo). O que as estatísticas de comércio exterior do Brasil mostram é a presença de produtos de maior intensidade na pauta de exportação, presença essa muito pequena e basicamente alavancada pela Embraer (Tabela 1).

Figura 7 Taxa de crescimento (média móvel) das importações brasileiras dos setores industriais por intensidade tecnológica, 1996-2010

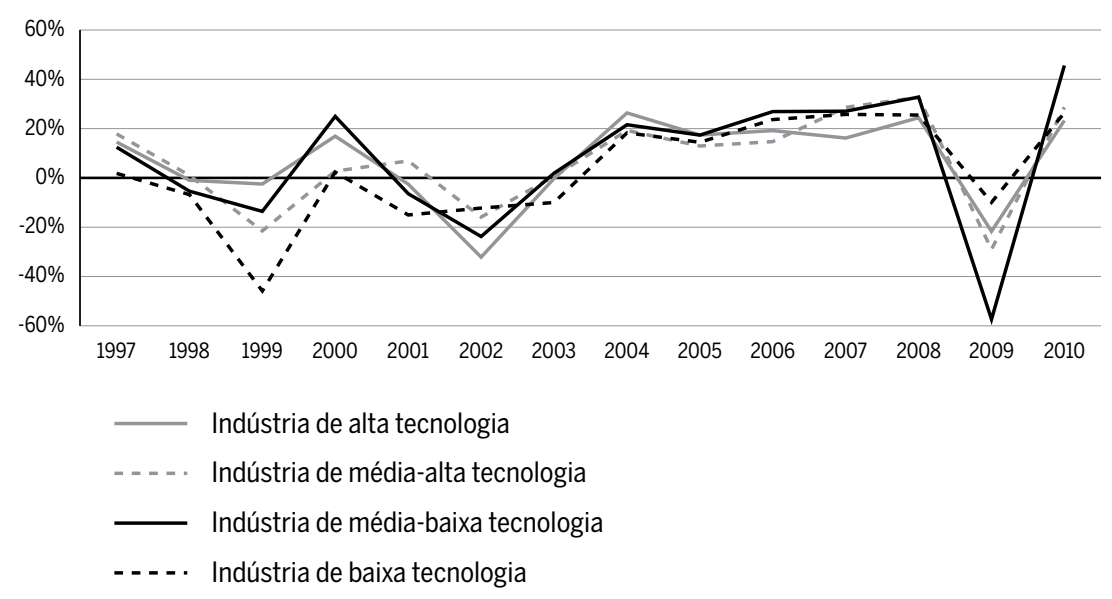

Fonte: Elaboração própria com base nos dados compilados pela SECEX/MDIC.

Nota: valor FOB. Classificação extraída de OECD, Directorate for Science, Technology and Industry, STAN Indicators, 2003. 
Tabela 1 Exportação das dez maiores empresas exportadoras do Brasil, US\$, 2000 e 2010

\begin{tabular}{|c|c|c|c|}
\hline & 2000 & US\$ FOB & \\
\hline Posição & & 55.085 .595 .326 & $\%$ \\
\hline 1 & Embraer S.A.* & 2.701.955.523 & 4,91 \\
\hline 2 & Companhia Vale do Rio Doce* & 1.596.124.497 & 2,90 \\
\hline 3 & Petrobras S.A.* & 1.456 .471 .035 & 2,64 \\
\hline 4 & Volkswagen do Brasil Ltda. & 1.128.862.112 & 2,05 \\
\hline 5 & Bunge Alimentos S.A. & 976.931 .904 & 1,77 \\
\hline 6 & Companhia Siderúrgica de Tubarão & 948.792 .531 & 1,72 \\
\hline 7 & Fiat Automóveis S.A. & 622.635 .482 & 1,13 \\
\hline 8 & Motorola Industrial Ltda. & 597.183 .927 & 1,08 \\
\hline 9 & Aracruz Celulose S.A.* & 587.000 .104 & 1,07 \\
\hline \multirow[t]{2}{*}{10} & General Motors do Brasil Ltda. & 572.617 .141 & 1,04 \\
\hline & 2010 & US\$ FOB & \\
\hline Posição & & 201.915.285.335 & $\%$ \\
\hline 1 & Vale S.A.* & 24.042.781.096 & 11,91 \\
\hline 2 & Petrobras S.A.* & 18.186.702.049 & 9,01 \\
\hline 3 & Bunge Alimentos S.A. & 4.300.622.399 & 2,13 \\
\hline 4 & Embraer S.A.* & 4.159.977.026 & 2,06 \\
\hline 5 & Samarco Mineração S.A. & 3.213.635.043 & 1,59 \\
\hline 6 & Cargill Agrícola S.A. & 3.028 .022 .863 & 1,50 \\
\hline 7 & Adm do Brasil Ltda. & 2.630 .964 .968 & 1,30 \\
\hline 8 & Braskem S.A.* & 2.470 .749 .533 & 1,22 \\
\hline 9 & Sadia S.A.* & 2.286 .365 .828 & 1,13 \\
\hline 10 & BRF - Brasil Foods S.A.* & 2.127.147.259 & 1,05 \\
\hline
\end{tabular}

Fonte: Elaboração própria com base nos dados compilados pela SECEX/MDIC do Boletim do Banco Central do Brasil (BCB Boletim/Ativ. Ec.).

Nota: valor FOB; $\left(^{*}\right)$ capital majoritário nacional.

Os produtos industriais perderam participação na pauta brasileira de exportação, conforme apresentado na Figura 3, e nota-se elevado dinamismo das commodities agrícolas e minerais a partir de meados dos anos 2000 (Sarti; Hiratuka, 2010; Sarti et al., 2010). Portanto, o recente crescimento das exportações brasileiras está relacionado, por um lado, à maior participação das commodities nas exportações totais brasileiras e, por outro, à queda da atividade em termos globais, sobretudo após a crise de 2008 (Almeida; Reis, 2012). 
Enquanto em 1996 o setor industrial que puxou as exportações brasileiras da indústria de alto conteúdo tecnológico foi o "setor de equipamentos de rádio, TV e comunicação" (correspondendo a 30,50\% das exportações dessa indústria), em 2010 foi o "setor aeronáutico e aeroespacial" (correspondendo a 50,30\% das exportações de alto conteúdo tecnológico) (Tabela A3, no Anexo), caracterizado pela elevada elasticidade-renda da demanda, sendo esse um resultado do bom desempenho da Embraer em âmbito internacional.

Pode-se verificar, valendo-se dos dados contidos na Tabela A3 (no Anexo), que os produtos da indústria farmacêutica (considerada indústria de alto conteúdo tecnológico) mantiveram praticamente seu desempenho exportador ínfimo, marcando sua "dependência" da indústria estrangeira, basicamente dependente da importação de princípios ativos de medicamentos. A indústria farmacêutica sempre foi deficitária (com déficit médio de US\$2,755 milhões no período 1996-2010), o que indica o desempenho insatisfatório dessa indústria, a despeito do seu reconhecimento como uma "opção estratégica" pelas políticas industriais dos governos Lula e Rousseff.

O baixo desempenho exportador das indústrias de alta intensidade tecnológica pode ser atribuído à falta de aptidão tecnológica. Melo, Fucidji e Possas (2015) analisam o hiato tecnológico brasileiro de acordo com o setor industrial por intensidade tecnológica. Tomando, por exemplo, o caso da indústria farmacêutica, os autores mostram que há baixo gasto em $\mathrm{P} \& \mathrm{D}$ e atividades inovativas nessa indústria. Ao utilizar informações sobre gasto em $\mathrm{P} \& \mathrm{D} /$ faturamento líquido como proxy para esforço inovativo, tem-se que, para a indústria farmacêutica brasileira, o indicador é 3,0\%, ao passo que, para os países europeus analisados (Bélgica, Dinamarca, Alemanha, Espanha, França, Itália, Holanda, Suécia e Noruega), a média é de 8,1\%. Apropriando-se dos dados da PINTEC/IBGE, os autores mostram ainda que apenas $20 \%$ das empresas do setor farmacêutico brasileiro declararam ter introduzido inovações de produto e processo.

O desempenho da indústria de médio-alto conteúdo tecnológico mostrou a "dependência" do país em relação a esses produtos como algo estrutural. A taxa de comércio (X/M) para esse tipo de indústria foi sempre deficitária (em 1996 foi de 0,53 e em 2010 foi de 0,48). Contrariamente, a indústria de médio-baixo conteúdo tecnológico e a de baixo conteúdo tecnológico mostraram-se com taxas de comércio maiores do que $1 \mathrm{em}$ todo o período 1996-2010 (Figura 4). 
Tem-se um movimento em formato de U-invertido da taxa de comércio da indústria de baixo conteúdo tecnológico, conforme demonstrado na Figura 4, o que comprova perda de dinamismo desse setor industrial. Percebe-se ainda que a indústria de médio-baixo conteúdo tecnológico teve esse mesmo padrão apresentado anteriormente (ou seja, uma tentativa de decolagem da taxa de comércio no início dos anos 2000 que não se sustentou e voltou aos patamares da década de 1990 no final dos anos 2000, e seu desempenho ainda ficou inferior à década de 1990), enquanto as indústrias de médio-baixo conteúdo tecnológico e alto conteúdo tecnológico mantiveram seu padrão de taxa de comércio inferior a 1 (Figura 4). É evidente que cada setor industrial possui as próprias características e é associado a diferentes níveis de oportunidades para inovação e diferentes elasticidade-renda da demanda (Dosi; Freeman; Fabiani, 1994). Desse modo, a elasticidade-renda dos produtos de baixa tecnologia é menor do que a dos grupos de maior intensidade tecnológica.

Para ilustrar o aumento das exportações brasileiras, foram expostas na Tabela 1 as principais empresas exportadoras do país. Das empresas que tiveram maior desempenho exportador (para dados disponíveis), a Embraer em 2000 foi a líder (cujo valor exportado correspondeu a 4,91\% de todo o exportado pelo país), enquanto, em 2010, a maior exportadora foi a Vale do Rio Doce (correspondendo a 11,91\% de toda a exportação). Não é por acaso que uma empresa de um setor maduro, como a Vale, aumentou suas exportações.

Fica claro que apenas uma única empresa de capital majoritariamente nacional em 2000 exportou mercadorias manufaturadas de alto conteúdo tecnológico, ou seja, aquelas que empenham maiores atividades tecnológicas para produção e possuem elevado valor agregado. As demais empresas de capital nacional, em 2000, que se encontravam entre as dez maiores exportadoras do Brasil, foram, na ordem, Vale do Rio Doce, Petrobras e Aracruz, todas elas exportadoras de commodities, em setores mais maduros e cujos produtos demandam relativamente menor intensidade tecnológica.

Em 2010, embora a Embraer tenha aumentado suas exportações 1,5 vez de 2000 a 2010, a Vale aumentou suas exportações em 15 vezes, estimulada pelos preços crescentes das commodities em mercados internacionais, chegando a exportar, no mesmo ano, soma superior a US $\$ 24$ bilhões (valor esse que representa $11,91 \%$ de toda a exportação brasileira). Outras empresas nacionais passaram a figurar no ranking das dez maiores exportadoras do Brasil: Braskem (indústria petroquímica), Sadia e BRF (ambas 
da indústria de processamento de alimentos). As principais exportadoras do país, em 2010, não são de produtos de alto conteúdo tecnológico (ao contrário, são basicamente de alimentos processados e mineração).

Analisando a qualidade das exportações ${ }^{12}$ brasileiras, tem-se que a participação das exportações da indústria manufatureira no total de exportações no período caiu paulatinamente de 1996 a 2010, de 84\% para 64\%. No entanto, nota-se participação praticamente constante dos produtos de média e alta intensidade tecnológica no total de produtos manufaturados exportados: em 1996, esses produtos correspondiam a 57\%, e, em 2010, a $58 \%$. O índice de qualidade das exportações brasileiras também se manteve praticamente constante, de 0,45 para 0,47 , no período. Em termos comparativos, em 2010, o referido índice para a Coreia do Sul, por exemplo, foi de 0,95 (Unido, 2007).

Do apresentado, deve-se ponderar o fato que, mesmo que se constatasse melhora significativa nas estatísticas de comércio de bens e serviços tecnológicos (e do índice de qualidade das exportações), pouco poderia ser argumentado sobre a capacidade de produção endógena de tecnologia, ${ }^{13}$ já que reduzidos encadeamentos produtivos e tecnológicos internos podem ter havido, e os resultados podem ter ficado restritos ao comércio exterior. Para Sarti e Hiratuka (2010) e Sarti et al. (2010), as exportações brasileiras não funcionaram como elemento dinamizador da estrutura industrial brasileira no período, não sendo capazes de liderar o crescimento econômico na ocasião.

12 O Industrial Export Quality Index elaborado pela UNIDO é a média aritmética simples da participação das exportações de produtos manufaturados no total de exportações e a participação dos produtos de média e alta intensidade tecnológica no total de produtos manufaturados exportados. Há ressalvas a serem feitas: além dos problemas relacionados à classificação dos produtos por níveis tecnológicos, há o problema sobre a extensão do valor agregado local nas atividades de exportação (um exportador que simplesmente reúne produtos de alta tecnologia é captado como "tão sofisticado" quanto um que projeta e produz produtos similares com componentes locais se ambos relatam os mesmos valores de exportação) (Unido, 2007). A lógica intrínseca a esse índice recai sobre o fato de a participação das manufaturas nas exportações totais capturarem o papel da produção na atividade de exportação e indiretamente a sua complexidade tecnológica, sua capacidade de tornar os produtos mais avançados e se mudar para áreas mais dinâmicas de crescimento das exportações. Já a participação dos produtos de média e alta intensidade tecnológica no total de produtos manufaturados exportados dá um peso positivo para atividades relativamente complexas, em razão de serem desejáveis para desempenho competitivo: uma estrutura mais complexa denota maturidade industrial, flexibilidade e capacidade de mover-se para as atividades de crescimento mais rápido (Unido, 2007).

13 É importante a presença de setores de alta tecnologia na indústria mexicana, embora concentrada em alguns setores, mas é reduzida a capacidade inovativa de suas empresas. $\bigcirc$ índice de qualidade das exportações mexicanas em 2010 foi 0,88 (Unido, 2007). 
Tabela 2 Índice de qualidade das exportações brasileiras, 1996-2010

\begin{tabular}{|c|c|c|c|c|c|}
\hline & $\begin{array}{r}\text { Participação } \\
\text { das expor- } \\
\text { tações da } \\
\text { indústria } \\
\text { manufatureira } \\
\text { no total de } \\
\text { exportações }\end{array}$ & $\begin{array}{r}\text { Participação } \\
\text { da indústria de } \\
\text { média e alta } \\
\text { intensidade } \\
\text { tecnológica no } \\
\text { total de produ- } \\
\text { tos manufatura- } \\
\text { dos exportados }\end{array}$ & $\begin{array}{r}\text { Participação } \\
\text { da indústria de } \\
\text { média-alta e } \\
\text { alta intensidade } \\
\text { tecnológica no } \\
\text { total de produ- } \\
\text { tos manufatura- } \\
\text { dos exportados }\end{array}$ & $\begin{array}{r}\text { Índice de } \\
\text { qualidade das } \\
\text { exportações - } \\
\text { Tipo } 1\left(^{*}\right)\end{array}$ & $\begin{array}{r}\text { Índice de } \\
\text { qualidade das } \\
\text { exportações - } \\
\text { Tipo } 2\left(^{*}\right)\end{array}$ \\
\hline & (A) & (B) & (C) & $(D)=[(A)+(B)] / 2$ & $(E)=[(A)+(C)] / 2$ \\
\hline 1996 & 0,84 & 0,57 & 0,32 & 0,45 & 0,58 \\
\hline 1997 & 0,80 & 0,60 & 0,37 & 0,48 & 0,59 \\
\hline 1998 & 0,81 & 0,61 & 0,39 & 0,50 & 0,60 \\
\hline 1999 & 0,82 & 0,60 & 0,38 & 0,49 & 0,60 \\
\hline 2000 & 0,83 & 0,65 & 0,43 & 0,54 & 0,63 \\
\hline 2001 & 0,82 & 0,61 & 0,40 & 0,51 & 0,61 \\
\hline 2002 & 0,81 & 0,61 & 0,39 & 0,50 & 0,60 \\
\hline 2003 & 0,80 & 0,60 & 0,37 & 0,49 & 0,59 \\
\hline 2004 & 0,80 & 0,62 & 0,37 & 0,50 & 0,59 \\
\hline 2005 & 0,79 & 0,64 & 0,40 & 0,52 & 0,60 \\
\hline 2006 & 0,78 & 0,64 & 0,39 & 0,52 & 0,58 \\
\hline 2007 & 0,76 & 0,64 & 0,38 & 0,51 & 0,57 \\
\hline 2008 & 0,72 & 0,64 & 0,36 & 0,50 & 0,54 \\
\hline 2009 & 0,68 & 0,58 & 0,35 & 0,46 & 0,52 \\
\hline 2010 & 0,64 & 0,58 & 0,36 & 0,47 & 0,50 \\
\hline
\end{tabular}

Fonte: Elaboração própria com base nos dados da Tabela A3 (no Anexo).

Nota: $\left(^{*}\right) 0$ índice de qualidade das exportações do tipo 1 segue a metodologia definida pela Unido (2007), conforme consta na Nota 13. $\left(^{* *}\right) 0$ índice de qualidade das exportações do tipo 2 leva em consideração a participação da indústria de média-alta e alta intensidade tecnológica, sendo, portanto, mais "conservador" que o de tipo 1.

Produtos de alta intensidade tecnológica possuem suas exportações associadas aos domínios dos ativos que permitem comandar uma cadeia de valor global. No entanto, conforme sugerem Sarti e Hiratuka (2010), os dados de comércio exterior sobre produtos de alto conteúdo tecnológico não mostram a capacidade do país de capturar o valor agregado dentro da cadeia produtiva global desse produto, mas mostram somente a intensidade na pauta de exportação da presença de tais produtos.

De um ponto de vista concreto, o comércio internacional durante as 
últimas décadas ampliou a importância das manufaturas, especialmente aquelas baseadas em alto conteúdo tecnológico (Mortimore; Vergara; Katz, 2001), porém, mesmo com a ligeira melhora, as manufaturas perderam participação na pauta exportadora em prol das commodities.

Pode-se inferir, portanto, que a economia brasileira não conseguiu, na última década do século XX e no alvorecer do século XXI, (re)configurar sua estrutura produtiva industrial para os padrões do novo paradigma tecnológico, não logrando ampliar sua competitividade internacional em manufaturas de alto conteúdo tecnológico, o que pode indiretamente mostrar sua baixa aptidão tecnológica. A participação das exportações brasileira de maior densidade tecnológica no comércio mundial é ainda insignificante, girando em torno de 0,50\% em 2010 (Figura 8).

\section{Figura 8 Exportações brasileiras de alto conteúdo tecnológico como proporção das} exportações mundiais e de países selecionados, 1990-2012

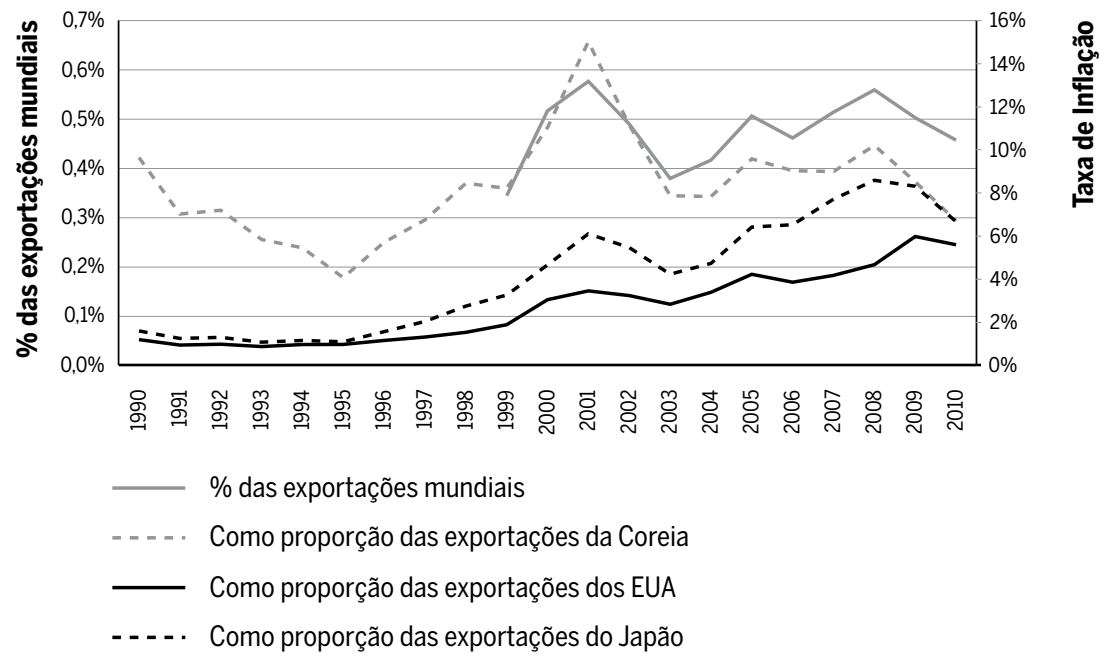

Fonte: Elaboração própria com base nos compilados pelo Banco Mundial da Comtrade Database das Nações Unidas.

Nota: Exportações de bens de alto conteúdo tecnológico são produtos com elevada intensidade de P\&D, como aeroespacial, computadores, produtos farmacêuticos, instrumentos científicos e equipamentos elétricos.

A fim de ilustrar a baixa presença das exportações brasileiras no mundo, verificou-se que aquelas da indústria de alto conteúdo tecnológico repre- 
sentam frações pequenas das exportações de países com forte capacidade inovativa. Em 2010, tais exportações brasileiras representam 5,58\%, $6,65 \%$ e 6,69\% do total de exportações com alto conteúdo tecnológico dos EUA, Japão e Coreia do Sul, respectivamente (Figura 8).

Para finalizar, evidencia-se uma recomposição do perfil exportador brasileiro a favor de produtos com menor intensidade tecnológica (que, a rigor, possuem efeitos de encadeamento mais limitados e com menor valor agregado), com exportações de manufaturados mais dependentes de mercados de renda média e baixa, particularmente os da América Latina (Belluzzo, 2008). A tecnologia que o Brasil exporta resulta em grande parte de imitação, adaptação ou melhoras de tecnologias já conhecidas, ao invés de resultar de inovações radicais de produtos e processos.

Uma importante observação pode ser feita com base nas informações apresentadas: o país possui pouco espaço de manobra para as oportunidades tecnológicas diante do novo paradigma tecnológico. Um tecido industrial que incorpora setores com graus elevados de complexidade tecnológica exibe dinâmica tecnológica e econômica superior aos demais setores, dadas as maiores oportunidades tecnológicas. Assim, pode-se constatar que o país, sempre deficitário em termos de comércio de bens e serviços de alto conteúdo tecnológico, possui tecido industrial com baixo grau de complexidade tecnológica.

\section{Comentários finais}

O ritmo de crescimento de uma nação encontra-se indissociavelmente ligado ao ritmo de suas atividades inovativas internas (capacitação tecnológica), que, por sua vez, sob certas condições, podem se beneficiar do fluxo de tecnologia e conhecimento oriundo do exterior. Com o objetivo de contribuir para a análise da possível relevância das importações e das exportações para o processo de transferência de tecnologia e de fomento do aprendizado, este artigo procurou explorar alguns dados de comércio internacional brasileiro.

A abordagem schumpeteriana entende que a inovação necessita conquistar outros mercados. Aqueles que se lançaram no mercado internacional (por definição, mais competitivo que o mercado doméstico) inovaram. Para exportar produtos intensivos em tecnologia, é preciso um tecido 
industrial inovador com setores tecnologicamente avançados e empresas capazes de "sair da arquibancada e entrar no jogo", com ajuda de uma política de Estado (Belluzzo, 2012a).

A aptidão tecnológica (não genérica), no atual paradigma tecnológico pode ser fomentada por meio: i) da comunidade internacional (informações incorporadas em bens de capital, informações incorporadas em indivíduos, blueprints, fornecedores estrangeiros, compradores estrangeiros, etc.); ii) da comunidade nacional (universidades, institutos de pesquisa, outras firmas, etc.); e iii) dos esforços internos das firmas (treinamento interno, $\mathrm{P} \& \mathrm{D}$, produção, etc.) (Kim, 2005 [1997]). O foco no comércio internacional brasileiro presente neste artigo tem por objetivo contribuir para análises a respeito do eventual papel de fornecedores e compradores estrangeiros como meio para fomentar/inibir o aprendizado e a capacitação tecnológica.

Embora o país tenha aumentado seu grau de abertura (conforme evidenciado pelos dados contidos na Figura 1), a inserção das exportações brasileiras de produtos industrializados com alto e médio-alto conteúdos tecnológicos é escassa e frágil, apoiando-se em uma marcante especialização de exportações de produtos de baixo e médio-baixo conteúdos tecnológicos.

Esse tipo de inserção verifica-se também com relação aos grandes exportadores nacionais, que exportam produtos de baixo conteúdo tecnológico (alimentos processados, minérios, etc.), com exceção da Embraer. Outros grandes exportadores são empresas cujo capital majoritário não é nacional; portanto, mesmo considerando que são unidades semiautônomas, as filiais/subsidiárias são condicionadas pelas ações de comando corporativo das transnacionais (fortemente influenciadas pela lógica financeira) e pelas oportunidades e restrições percebidas no ambiente doméstico, não estando comprometidas com estratégias de longo prazo de desenvolvimento nacional, mas sim com as próprias estratégias de valorização de capital.

Existe uma diferença no perfil de inserção internacional das empresas de capital nacional e das empresas de capital estrangeiro. Em estudo feito por Hiratuka e Negri (2004), chegou-se à conclusão de que as empresas transnacionais localizadas no Brasil importam produtos com mais intensidade tecnológica do que as empresas brasileiras. Assim, as transnacionais possuem maior volume de importação de produtos relativamente mais tecnológicos, o que pode ser explicado pela dependência de tecnologia das filiais das empresas estrangeiras com respeito a suas matrizes, corroborando ainda a relação de comércio entre a filial e a matriz. Ademais, de acordo 
com Laplane e Negri (2004), as empresas transnacionais são mais integradas ao comércio mundial do que as empresas domésticas brasileiras. Desse modo, o comércio entre matriz e filial de produtos tecnológicos e de máquinas e equipamentos não resulta necessariamente em transferência a terceiras partes ou difusão ao setor produtivo, salvo por meio de efeitos de transbordamentos sobre os encadeamentos produtivos que possui com outras empresas, se for o caso.

A problemática proposta por Hiratuka e Negri (2004) pode indicar a tendência das empresas transnacionais de internalizar a produção que faz uso intensivo de tecnologia, ao invés de comercializá-la livremente no mercado. Exatamente por serem mais integradas ao comércio mundial, as filiais localizadas no Brasil têm maior acesso a mercados internacionais e outras vantagens, dentre as quais é possível citar, economias de escala, acesso facilitado ao crédito e às novas tecnologias (Laplane; Negri, 2004).

Desde a abertura comercial empreendida pelo Brasil, a partir de meados dos anos 1980, pode-se notar que, de fato, houve ampliação do comércio exterior brasileiro (analisado aqui somente em termos de mercadorias de acordo com seu conteúdo tecnológico); houve, porém, propensão a importar (produtos com densidade tecnológica) superior ao verificado pelas exportações, repercutindo negativamente sobre o saldo comercial do país. Em outras palavras, o país introduziu internamente tecnologias modernas, mas foi incapaz de agregar maior tecnologia aos produtos aqui produzidos e de agregar valor e colocá-los no mercado internacional.

Como resultado, o Brasil não consegue consolidar um processo de industrialização que resulte em exportações de produtos com alto conteúdo tecnológico, de modo que grande parte das exportações segue sendo de produtos com baixo valor agregado. Adicionalmente, é possível depreender, a partir do fato de as exportações brasileiras de produtos industrializados com alto e médio-alto conteúdos tecnológicos serem relativamente escassas, que o país está ainda preso a um padrão de produção relativamente obsoleto. ${ }^{14}$

O Brasil não logrou elevar sua competitividade internacional por causa de sua pobre inserção nas manufaturas dinâmicas (produtos de alto e 14 Em termos setoriais, essa afirmação não é verdadeira. Há setores em que o país se encontra na fronteira tecnológica, como é o caso da aviação civil, representada pelo bom desempenho internacional da Embraer, por exemplo. Por essa questão, deve-se, mais uma vez, ressalvar que o processo inovativo é específico a cada setor e a cada firma em particular. Assim, a transferência internacional de tecnologia também é específica a cada setor e a cada firma. 
médio-alto conteúdo tecnológico) em mercados internacionais, tanto por via das empresas nacionais quanto por meio de sua participação em sistemas internacionais de produção integrada, comandados pelas grandes corporações transnacionais (as quais têm estratégias claramente de market seeking, no caso brasileiro).

Embora a importação de tecnologia (corporificada em produtos de alto conteúdo tecnológico) possa se constituir em canal de transferência internacional de tecnologia, essa apenas se efetiva se as importações forem articuladas a processos internos de aprendizado e acumulação de conhecimento. Além disso, nem todos os modos de importação tecnológica contribuem para o aprendizado doméstico. Depende da maneira pela qual a tecnologia está ligada a fatores complementares, se ela pode ser adquirida de outras fontes, da velocidade que ela muda, do grau de desenvolvimento das aptidões tecnológicas locais, assim como das políticas implementadas para estimular sua transferência e seu aprofundamento. Em suma, depende do sistema de inovação.

Se a tecnologia importada tiver caráter complementar à tecnologia local, pode ser possível que se estimule a ampliação da aptidão tecnológica doméstica por meio, por exemplo, de aprendizado. Caso contrário, se a tecnologia do exterior é substituta da tecnologia local, há prejuízos à capacidade local de geração de tecnologia (Fransman, 1986). Em síntese, a mera importação não se traduz em desenvolvimento.

Ademais, a tecnologia importada pode ser utilizada meramente como meio para a obtenção de medidas pontuais de aumento da competitividade via aquisição de projetos e especificações para novos produtos, equipamentos e know-how operacional para novos processos. O país receptor da nova tecnologia pode ter retardado ou inibido o desenvolvimento de tecnologias similares por empresas locais, atrasando o desenvolvimento tecnológico do país receptor e reproduzindo a "síndrome de dependência tecnológica", caso a capacitação tecnológica doméstica seja insuficiente.

O investimento físico em novas máquinas adquiridas do exterior deve ser complementado por investimentos intangíveis, daí a necessidade tanto de políticas de transferência de tecnologia quanto de capacitação tecnológica, em prol do desenvolvimento nacional, permitindo a participação das empresas nacionais em cadeias globais de valor em atividades de alto conteúdo tecnológico. 
É meritório certificar que, para um entendimento adequado da transferência internacional de tecnologia, se devem levar em consideração as especificidades de cada setor industrial. Desse modo, é difícil chegar a um quadro compreensivo do verdadeiro impacto do comércio de bens e serviços tecnológicos e de bens de capital para o emparelhamento e o desenvolvimento econômico.

Outro ponto que merece destaque é o fato de o paradigma das TICs levar em conta, cada vez mais, tecnologias não tangíveis. Assim, a importação de máquinas e equipamentos não incorpora diversos elementos, tornando mais complexo e especializado o acesso às tecnologias externas. Por conseguinte, para que ocorra o emparelhamento, não basta que ocorra a transferência de tecnologia via importação de máquinas e equipamentos.

Quanto à exportação de produtos com alto conteúdo tecnológico, essa pode ser usada como indicador do domínio tecnológico de uma nação, embora de forma imprecisa.

Em síntese, as variáveis relativas ao mercado internacional (importação e exportação de produtos com alto conteúdo tecnológico, por exemplo) contribuem para o entendimento do processo dinâmico de evolução das vantagens competitivas das nações, e a evolução de tais vantagens sustenta o emparelhamento/divergência internacional.

Portanto, a importação de tecnologia e a aptidão tecnológica doméstica são fundamentais para o estudo da "construção" de vantagens competitivas dinâmicas no mercado internacional por parte das nações atrasadas, e, com base nos dados exploratórios apresentados, percebe-se que o Brasil está ficando para trás, já que o país manteve certa dinâmica exportadora em função de suas commodities, retrocedendo como exportador de manufaturas, especialmente de bens de alto conteúdo tecnológico.

\section{Referências}

AKYUZ, Y. Impasses do desenvolvimento. Novos Estudos CEBRAP, v. 72, p. 41-58, 2005.

ALBUQUERQUE, E. M. National systems of innovation and non-OCED countries: notes about a rudimentary and tentative 'tipology'. Revista de Economia Política, v. 19, n. 4, p. 35-52, 1999.

ALBUQUERQUE, E. M. Immature systems of innovation: introductory notes about a comparison between South Africa, India, Mexico and Brazil based on science and technology statistics. Texto para Discussão n. 221. Belo Horizonte (MG): Centro de Desenvolvimento e 
Planejamento Regional (Cedeplar), Universidade Federal de Minas Gerais (UFMG), 2003.

ALMEIDA, J. G. Alcance e lacunas da nova política industrial. Texto para Discussão n. 196. Campinas (SP): Instituto de Economia (IE), Universidade Estadual de Campinas (Unicamp), 2011.

ALMEIDA, J. G.; REIS, C. F. B. A maior relevância brasileira nas importações mundiais. Texto para Discussão n. 213. Campinas (SP): Instituto de Economia (IE) da Universidade Estadual de Campians (Unicamp), 2012.

AUREA, A. P.; GALVÃO, A. C. F. Importação de tecnologia, acesso às inovações e desenvolvimento regional: o quadro recente no Brasil. Texto para Discussão n. 616. Brasília: Instituto de Economia Aplicada (IPEA), 1998.

BELL, M.; CASSIOLATO, J. E. The access of developing countires to new technologies: the need for new approaches to management and policy for technology imports in Brazilian industry. Estudo da Competitividade Brasileira. Campinas (SP), 1993.

BELlUZZO, L. G. A inserção na economia global. Le Monde Diplomatique, São Paulo, 4 jul. 2008.

BELLUZZO, L. G. A indústria em perigo. Valor Econômico, São Paulo, 4 set. 2012a.

BELLUZZO, L. G. Os desafios da (re)industrialização. Valor Econômico, São Paulo, 3 abr. 2012 b.

CANO, W. A desindustrialização no Brasil. Economia \& Sociedade, v. 21, Número Especial, p. 831-851, 2012.

CANO, W.; SILVA, A. L. G.. Política Industrial do Governo Lula. In: MAGALHÃES, J. P. A. et al. (Orgs.). Os anos Lula: contribuições para um balanço crítico 2003-2010. Rio de Janeiro: Garamond, 2010. p. 181-208.

CARNEIRO, R. Desenvolvimento em crise: a economia brasileira no último quarto do século XIX. São Paulo: Editora UNESP, 2002. 444 p.

CHIARINI, T.; RAPINI, M. S.; VIEIRA, K. P. Produção de novos conhecimentos nas universidades federais e as políticas públicas brasileiras recentes de CT\&I. Economia \& Tecnologia, v. 10, n. 3, p. 71-98, 2014.

COUTINHO, L.; BELLUZZO, L. G. Desenvolvimento e estabilização sob finanças globalizadas. Economia \& Sociedade, v. 7, p. 129-154, 1996.

DOSI, G.; FREEMAN, C.; FABIANI, S. The process of economic development: introducing some stylized facts and theories on technologies, firms and institutions. Industrial and Corporate Change, v. 3, n. 1, p. 1-45, 1994.

ERBER, F. S. Escolha de tecnologias, preços dos fatores de produção e dependência: uma contribuição ao debate. Pesquisa e Planejamento Econômico, v. 2, n. 1, p. 105-116, 1972.

ERBER, F. S. Perspectivas da América Latina em ciência e tecnologia. Parcerias Estratégicas, v. 8, p. 181-200, 2000.

FAJNZYLBER, F. Industrialización en América Latina: de la 'caja negra' al 'casillero vacio'. Comparación de patrones contemporáneos de industrialización. Santiago: CEPAL (ONU), 1989. $176 \mathrm{p}$.

FIGUEIREDO, N. F. A transferência de tecnologia no desenvolvimento industrial do Brasil. Rio de Janeiro: IPEA/INPES, 1972. 360 p. 
FRANSMAN, M. Technology and economic development. United Kingdom: Wheatsheaf Books, 1986. $161 \mathrm{p}$.

FREEMAN, C. El reto de la innovación: la experiencia de Japón. Caracas (Venezuela): Editorial Galac, 1987. 200 p.

FREEMAN, C. The 'National System of Innovation' in historical perspective. Cambridge Journal of Economics, v. 19, p. 5-24, 1995.

FREEMAN, C.; SOETE, L. A economia da inovação industrial. Campinas (SP): Editora da Unicamp, 2008 [1974]. 813 p.

FURTADO, A.; CARVALHO, R. Q. Padrões de intesidade tecnológica da indústria brasileira: um estudo comparativo com os países centrais. São Paulo em Perspectiva, v. 19, n. 1, p. 70-84, 2005.

FURTADO, C. Os ares do mundo. São Paulo: Paz e Terra, 1991. 340 p.

FURTADO, C. O capitalismo global. São Paulo: Paz e Terra, 1998. 83 p.

HASENCLEVER, L.; CASSIOLATO, J. E. Capacidad tecnológica empresarial brasileña y transferencia de tecnología. Revista de Economía y Empresas, v. 34, n. XII, p. 15-31, 1998.

HATZICHRONOGLOU, T. Revision of the high-technology sector and product classification. OECD Science, Technology and Industry Working Papers 1997/02. Paris: Organisation for Economic Co-operation and Development (OECD), 1997.

HIRATUKA, C.; NEGRI, F. D. Influencia del origen del capital sobre los patrones del comercio exterior brasileño. Revista de la CEPAL, v. 82, p. 121-137, 2004.

HIRATUKA, C.; SARTI, F. Transformações na estrutura produtiva global, desindustrialização e desenvolvimento industrial no Brasil: uma contribuição ao debate. Texto para Discussão n. 255. Campinas (SP): Instituto de Economia (IE), Universidade Estadual de Campinas (Unicamp), 2015.

JAMES, D. D. The impact of technology imports on indigenous technological capacity: the case study of Mexico. Working Paper n. 184. Gevene (Switzerland): World Employment Programme Research at International Organization (ILO), 1988.

KATZ, J. Importación de tecnología, aprendizaje e industrialización dependiente. Ciudad de Mexico: Fondo de Cultura Económica, 1976. 224 p.

KATZ, J. Pasado y presente del comportamiento tecnológico de América Latina. Serie Desarrollo Productivo de La CEPAL, n. 75. Santiago: División de Desarrollo Productivo y Empresarial de la CEPAL, 2000.

KATZ, J. A dinâmica do aprendizado tecnológico no período de substituição das importações e as recentes mudanças estruturais no setor industrial da Argentina, do Brasil e do México. In: KIM, L.; NELSON, R. R. (Orgs.). Tecnologia, aprendizado e inovação: as experiências das economias de industrialização recente. Campinas (SP): Editora da Unicamp, 2005. cap. 10, p. 413-448.

KIM, L. Da imitação à inovação: a dinâmica do aprendizado tecnológico da Coreia. Campinas (SP): Editora da Unicamp, 2005 [1997]. 388 p.

KOELLER, P. O papel do Estado e a Política de Inovação. Nota Técnica. Rio de Janeiro: Instituto de Economia (IE) da Universidade Federal do Rio de Janeiro (UFRJ), 2007. 
LAPLANE, M.; NEGRI, F. D. Impactos das empresas estrangeiras sobre o comércio exterior brasileiro: evidências da década de 90. Economia (UFPR), v. 30, n. 1, p. 31-48, 2004.

LAPLANE, M.; SARTI, F. Investimento Direto Estrangeiro e a retomada do crescimento sustentado nos anos 90. Economia \& Sociedade, v. 8, p. 143-181, 1997.

LUNDVALL, B.-A.; JOSEPH, K. J.; VANG, J.; CHAMINADE, C. Innovation system research and developing countries. In: LUNDVALL, B.-A.; JOSEPH, K. J., et al. (Orgs.). Handbook of innovation systems and developing countries: building domestic capabilities in a global setting. Northampton (USA): Edward Elgar, 2009. cap. 1, p. 1-32.

LUNDVALL, B. A. Innovation as an interactive process: from user-producer interaction to the national system of innovation. In: DOSI, G.; FREEMAN, C., et al. (Orgs.). Technical change and Economic Theory. London: Pinter Publishers, 1988. cap. 17, p. 349-369.

LUNDVALL, B. A. National Systems of Innovation: towards a theory of innovation and interactive learning. London: Printer Publishers, 1992.

MATESCO, V. R.; HASENCLEVER, L. Indicadores de esforço tecnológico: comparação e implicações. Texto para Discussão n. 442. Brasília: Instituto de Pesquisa Econômica Aplicada (IPEA), 1998.

MELO, T. M.; FUCIDJI, J. R.; POSSAS, M. L. Política industrial como política de inovação: notas sobre hiato tecnológico, políticas, recursos e atividades inovativas no Brasil. Revista Brasileira de Inovação, v. 14, Número Especial, p. 11-36, 2015.

MORTIMORE, M.; VERGARA, S.; KATZ, J. La competitividad internacional y el desarrollo nacional: implicancias para la política de Inversión Extranjera Directa (IED) en América Latina. Serie Desarrollo Productivo de La CEPAL, n. 107. Santiago de Chile: Unidad de Inversiones y Estrategias Empresariales, División de Desarrollo Productivo y Empresarial, CEPAL/ UN, 71 p., 2001.

MUNIZ, S. Investimento recente, capacitação tecnológica e competitividade. São Paulo em Perspectiva, v. 14, n. 3, p. 98-107, 2000.

NELSON, R. R. National Innovation Systems: a comparative analysis. New York: Oxford University Press, 1993. 541 p.

OECD. Science, Technology and Industry Scoreboard. Paris: Organisation for Economic Co-Operation and Development (OECD), 2003.

PACHECO, C. A.; ALMEIDA, J. G. D. A política de inovação. Texto para Discussão n. 210. Campinas (SP): Instituto de Economia (IE), Universidade Estadual de Campinas (Unicamp), 2013.

PRADO, L. C. D. Fábio Erber: o economista e suas circunstâncias. Revista de Economia Contemporânea, v. 15, n. 1, p. 198-215, 2011.

RADOSEVIC, S. International technology transfer and catch-up in economic development. Cheltenham (UK): Edward Elgar, 1999. 284 p.

RANGEL, A. S. Diagnóstico de CeT no Brasil. Documento de Governo. Brasília: Ministério da Ciência, Tecnologia e Inovação (MCTI), 12 p., 1995.

SARTI, F.; HIRATUKA, C. Indústria mundial: mudanças e tendências recentes. Texto para Discussão n. 186. Campinas (SP): Instituto de Economia (IE) da Universidade Estadual de Campinas (Unicamp), 2010. 
SARTI, F.; HIRATUKA, C.; ROCHA, F.; WILKINSON, J.; GARCIA, R.; SABBATINI, R.; BAMPI, S. Perspectivas do investimento na indústria. Rio de Janeiro: Synergia, 2010. 344 p.

SIMON, D. F. International business and the transborder movement of technology: a dialectic perspective. In: AGMON, T.; GLINOW, M. A. V. (Orgs.). Technology transfer in international business. New York: Oxford University Press, 1991. cap. 1, p. 5-28.

SUNKEL, O. Capitalismo transnacional y desintegración nacional. El Trimestre Económico, v. 150, p. 3-61, 1971.

TAVARES, M. C. Da substituição de importações ao capitalismo financeiro. Rio de Janeiro: Zahar Editores, 1981. 263 p.

UNIDO. Structure of the CIP indicators and the industrial development scorboard. Technical Notes. Vienna: United Nations Industrial Development Organization (UNIDO/UN), 2007.

VERA-VASSALLO, A. La inversión extranjera y el desarrollo competitivo en América Latina y el Caribe. Revista de la CEPAL, v. 60, p. 129-149, 1996.

ZAWISLAK, P. A.; FRACASSO, E. M.; TELLO-GAMARRA, J. Intensidade tecnológica e capacidade de inovação de firmas industriais. In: CONGRESSO LATINO-IBEROAMERICANA DE GESTÃO DE TECNOlOGIA, 15., 2013, Porto (Portugal). Anais... Porto (Portugal), 2013.

\section{Sobre os autores}

Tulio Chiarini-tulio.chiarini@int.gov.br

Instituto Nacional de Tecnologia, Ministério da Ciência, Tecnologia e Inovação - INT/MCTI, Brasília, DF.

Ana Lucia Gonçalves da Silva - algsilva@unicamp.br

Instituto de Economia, Universidade Estadual de Campinas - IE/UNICAMP, Campinas, SP.

Os pensamentos e as ideias expressos neste trabalho não refletem necessariamente aqueles do INT/MCTI. Os autores gostariam de agradecer os pareceristas anônimos da Nova Economia pelas contribuições. Os eventuais erros são de inteira responsabilidade dos autores. Esta é uma versão revisada e ampliada do artigo intitulado "Comércio de produtos tecnológicos e transferência internacional de tecnologia: análise exploratória do caso brasileiro nas décadas de 1990 e 2010", apresentado no XLII Encontro Nacional de Economia da ANPEC, 2014, Natal.

\section{Sobre 0 artigo}

Recebido em 28 de julho de 2014. Aprovado em 21 de julho de 2015. 


\section{Anexo}

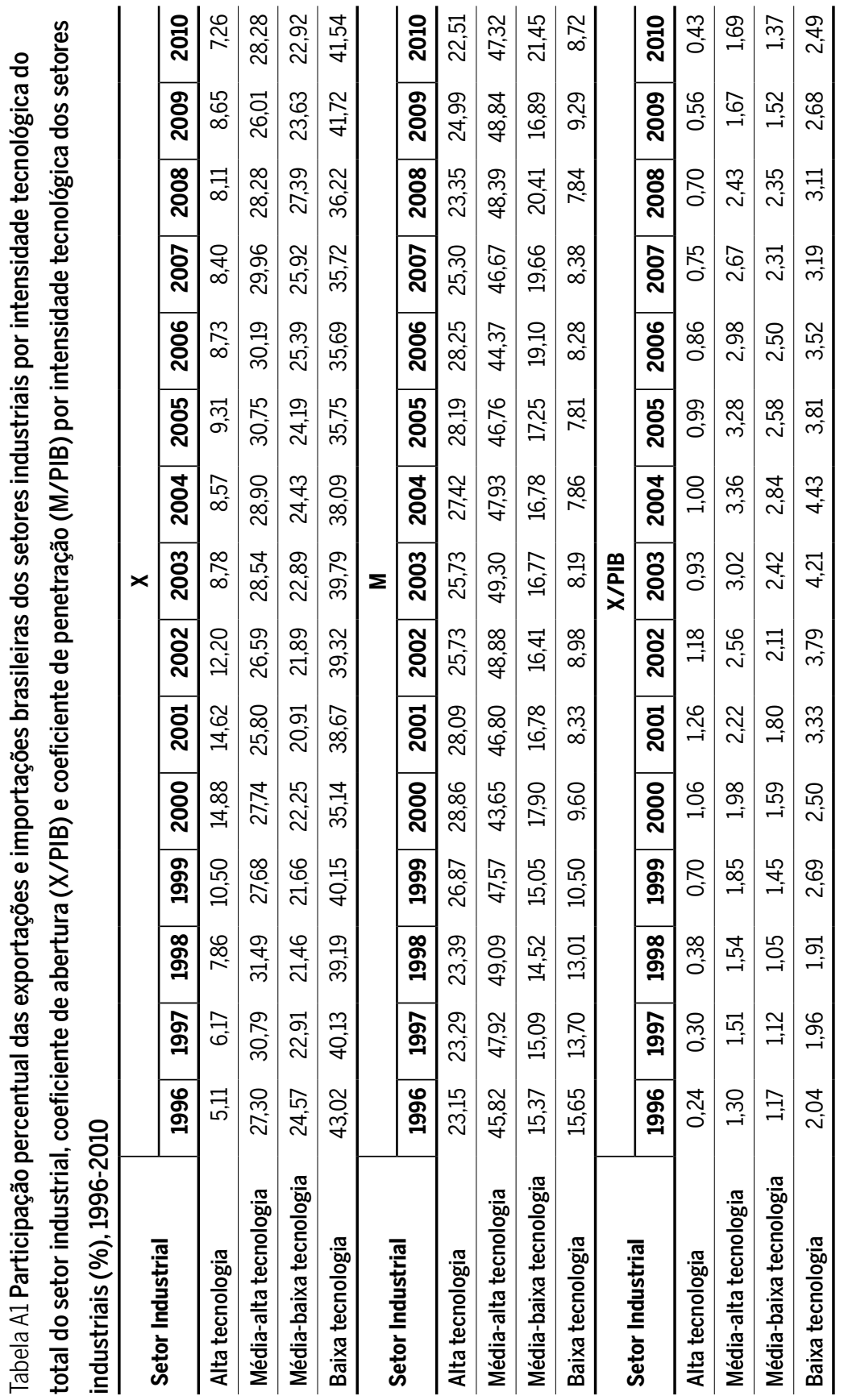




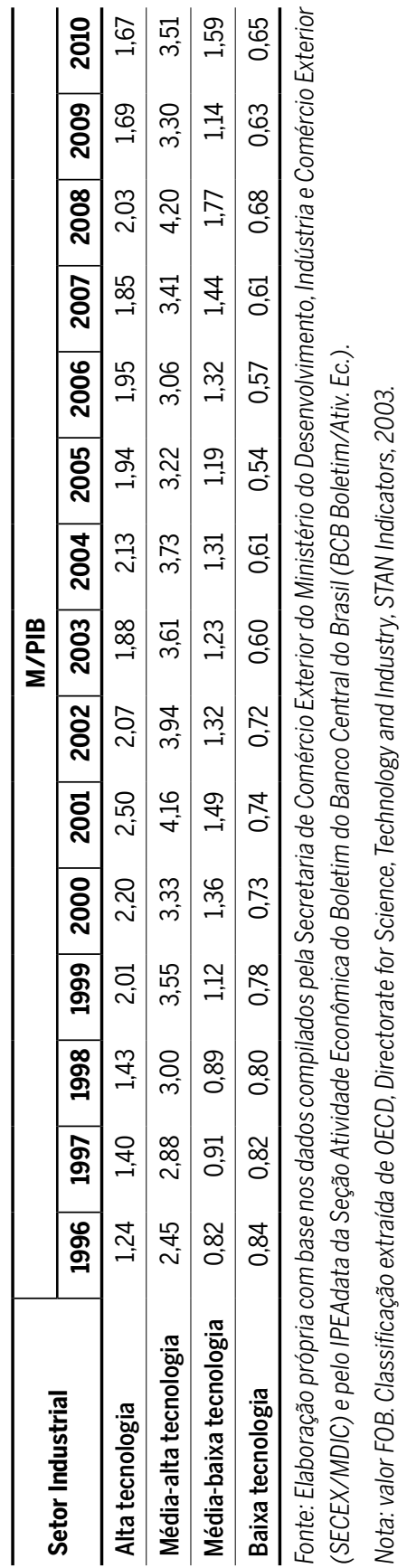




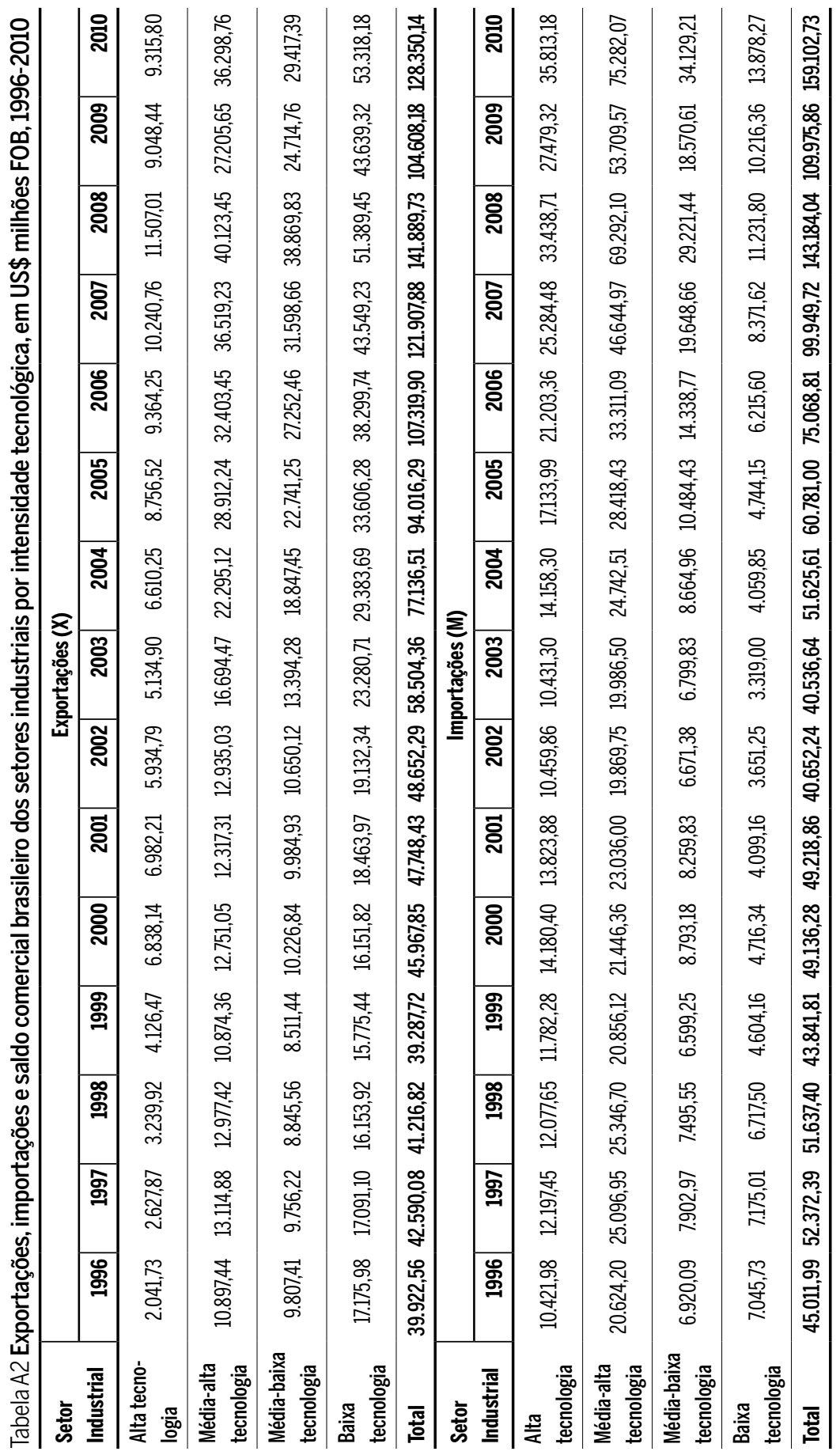




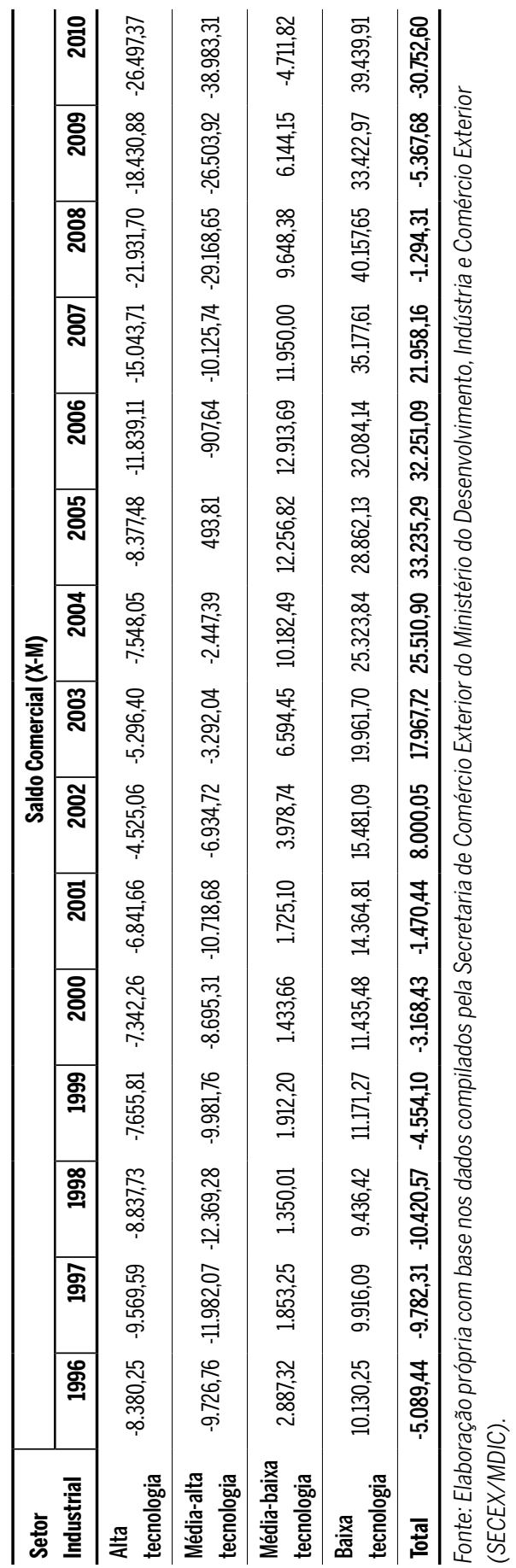




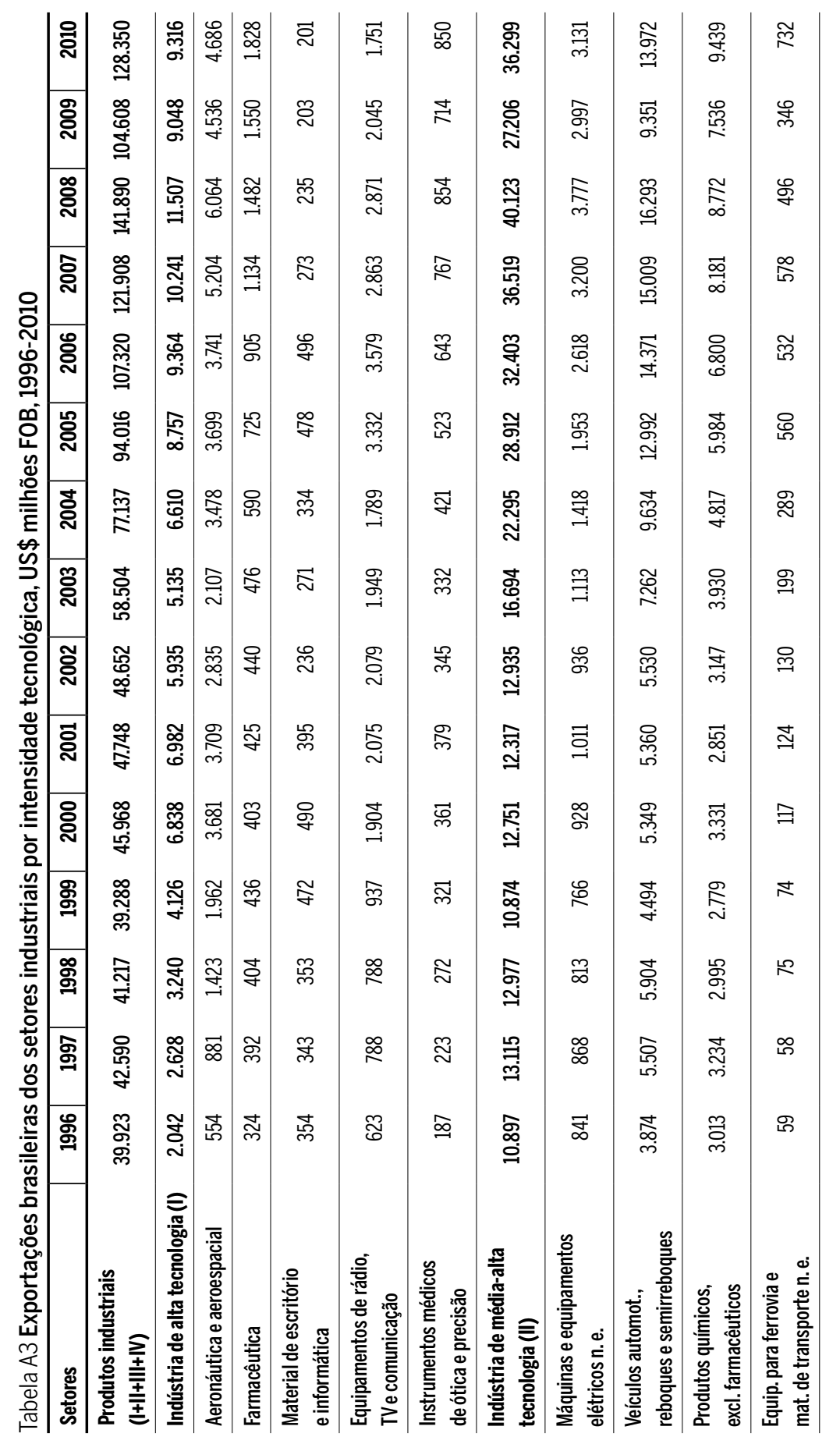




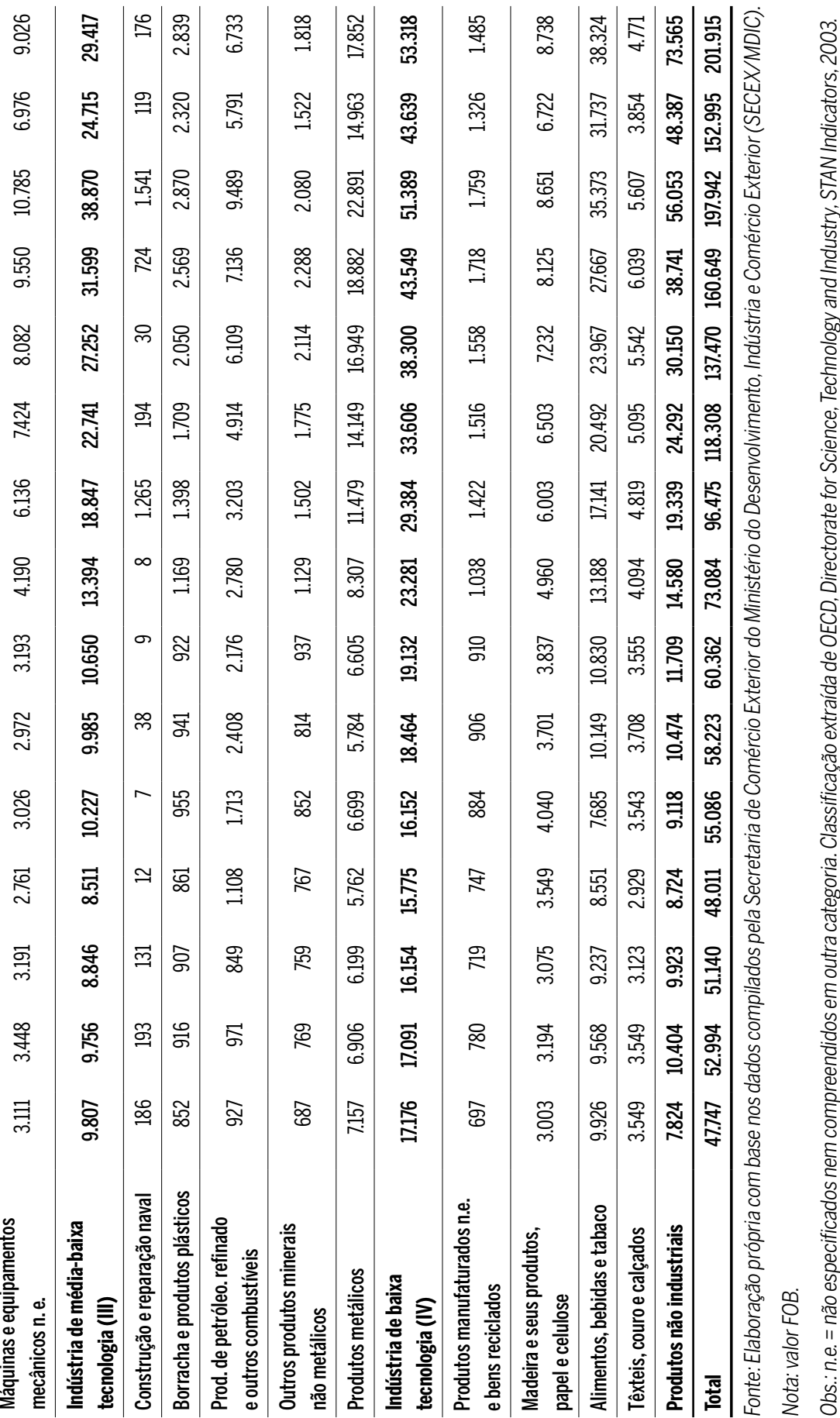




\begin{tabular}{|c|c|c|c|c|c|c|c|c|c|c|c|c|c|}
\hline & 을 & 棝 & 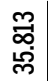 & $\begin{array}{l}\stackrel{2}{0} \\
\dot{0} \\
+\end{array}$ & 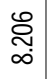 & ণ্ণ & $\stackrel{\text { 尔 }}{\underset{9}{9}}$ & 兽 & ஸ્ઝ & $\underset{\pi}{\stackrel{9}{N}}$ & $\begin{array}{l}\underset{g}{g} \\
\text { 号 }\end{array}$ & $\begin{array}{l}\text { L } \\
\text { 岕 } \\
\text { مై }\end{array}$ & $\underset{\sim}{\stackrel{\sim}{\leftrightarrows}}$ \\
\hline & ઠें & $\begin{array}{l}\stackrel{0}{S} \\
\text { 亏̆ }\end{array}$ & $\underset{\stackrel{\rho}{f}}{\stackrel{\sim}{\sim}}$ & $\stackrel{\stackrel{\mathscr{m}}{7}}{+}$ & 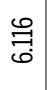 & $\stackrel{\infty}{\stackrel{\infty}{\sim}}$ & 형 & 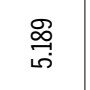 & 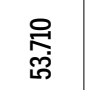 & ஜु & 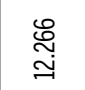 & $\begin{array}{l}\text { ஜू } \\
\text { O̊ं. }\end{array}$ & ఇ̊ \\
\hline & 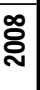 & 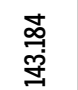 & 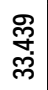 & 灾 & 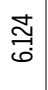 & 导 & 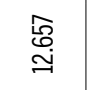 & 仓ु & 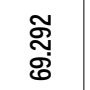 & $\begin{array}{l}\text { 电 } \\
\text { ம) }\end{array}$ & $\begin{array}{l}\vec{D} \\
\stackrel{+}{+}\end{array}$ & $\begin{array}{l}\vec{\infty} \\
\infty \\
\infty \\
\text { ஸे }\end{array}$ & $\underset{\overbrace{}}{\overparen{్}}$ \\
\hline & ర్లి & $\begin{array}{l}\text { 용 } \\
\text { ᄋ̆ }\end{array}$ & $\begin{array}{l}\text { 志 } \\
\text { స్ }\end{array}$ & $\underset{\stackrel{\mathcal{F}}{\tilde{m}}}{ }$ & $\begin{array}{l}\infty \\
\stackrel{\infty}{\infty} \\
\underset{+}{*}\end{array}$ & ن. & 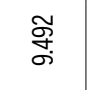 & $\begin{array}{l}\stackrel{g}{\infty} \\
\underset{+}{+}\end{array}$ & 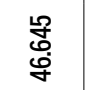 & $\underset{\forall}{\stackrel{f}{f}}$ & $\underset{\overbrace{}}{\approx}$ & $\begin{array}{l}\mathscr{m} \\
\text { Oू. } \\
\text { g. }\end{array}$ & 寻 \\
\hline & ్ㅠ & $\begin{array}{l}\text { ஜ̊ } \\
\text { 몸 }\end{array}$ & 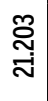 & $\stackrel{\stackrel{\Omega}{7}}{\sim}$ & $\underset{\widetilde{\varpi}}{\overparen{ల}}$ & $\underset{\sim}{\stackrel{\Omega}{\sim}}$ & $\underset{\substack{+\infty}}{+}$ & 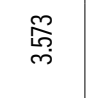 & $\begin{array}{l}\text { 户ี } \\
\text { ल्ల }\end{array}$ & 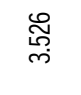 & 悐 & $\begin{array}{l}\stackrel{\circ}{\circ} \\
\stackrel{\leftrightarrow}{\rightarrow}\end{array}$ & 总 \\
\hline & ర్ని & $\begin{array}{l}\vec{\circ} \\
\stackrel{\delta}{\delta}\end{array}$ & 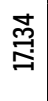 & 㞭 & 용 & స్త & $\underset{N}{\stackrel{N}{N}}$ & $\stackrel{\widetilde{\widetilde{N}}}{\mathrm{~N}}$ & $\begin{array}{l}\stackrel{\infty}{\exists} \\
\text { 心 }\end{array}$ & 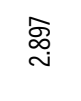 & $\begin{array}{l}\widehat{\varrho} \\
\text { ம) }\end{array}$ & 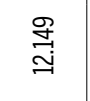 & ঙ্ণ \\
\hline & ర్సి & 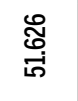 & $\begin{array}{l}\stackrel{\infty}{g} \\
\underset{\exists}{\sharp}\end{array}$ & $\underset{\Xi}{\mathbb{I}}$ & $\underset{\mathscr{O}}{\mathscr{O}}$ & 思 & 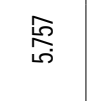 & 总 & 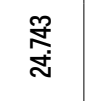 & 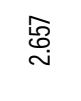 & 앾 & 壱 & 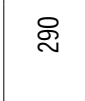 \\
\hline & ర్ & 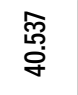 & 突 & 当 & $\stackrel{\widetilde{N}}{\sim}$ & $\underset{\sim}{\underset{T}{ت}}$ & 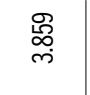 & $\underset{\infty}{\widehat{\infty}}$ & $\begin{array}{l}\text { ळ } \\
\text { ळ. }\end{array}$ & 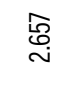 & $\underset{m}{\stackrel{m}{m}}$ & 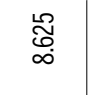 & Ш્ડ \\
\hline & ర్ & $\begin{array}{l}\text { గ్ర } \\
\text { O̊ }\end{array}$ & $\begin{array}{l}\text { 영 } \\
\text { 으 }\end{array}$ & $\underset{\Xi}{\cong}$ & $\underset{\sim}{\sim \sim}$ & 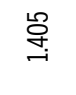 & 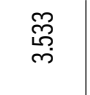 & ळ্ণ & $\begin{array}{l}\stackrel{0}{0} \\
\stackrel{\infty}{\text { g }}\end{array}$ & 衣 & 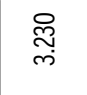 & 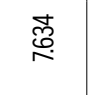 & ஜ \\
\hline & ర్రి & $\begin{array}{l}\text { 옴 } \\
\text { \% }\end{array}$ & $\begin{array}{l}\underset{\Phi}{\mathbb{S}} \\
\ddot{m}\end{array}$ & 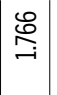 & 胥 & 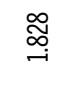 & 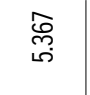 & ্ֻণ & ஜ్ర్ల & $\underset{\mathscr{\infty}}{\mathscr{\infty}}$ & 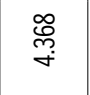 & 志 & $\underset{\sim}{\sim}$ \\
\hline & ర్సి & $\begin{array}{l}\mathscr{m} \\
\stackrel{9}{9}\end{array}$ & $\begin{array}{l}\stackrel{\mathscr{O}}{二} \\
\underset{\exists}{\exists}\end{array}$ & $\underset{\$}{\stackrel{F}{-}}$ & $\underset{\sim}{\sim}$ & $\underset{్}{\widetilde{\sigma}}$ & శ్రి & $\underset{\sim}{\stackrel{\Xi}{\sigma}}$ & $\frac{O}{\mathbb{N}}$ & $\underset{\sim}{\stackrel{\Re}{\sim}}$ & 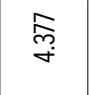 & $\underset{\infty}{\stackrel{\mathscr{D}}{\infty}}$ & 芯 \\
\hline & ஓ & 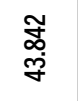 & 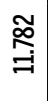 & 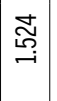 & $\stackrel{\substack{\sim \\
\sim}}{\sim}$ & 苞 & $\underset{+}{\stackrel{g}{+}}$ & $\stackrel{\infty}{\stackrel{2}{ }}$ & $\begin{array}{l}\text { 员 } \\
\text { Dิ }\end{array}$ & $\underset{ }{\overparen{\sim}}$ & 芦 & $\stackrel{\widehat{O}}{\curvearrowright}$ & 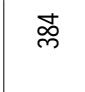 \\
\hline & \% & $\begin{array}{l}\widehat{\tilde{B}} \\
\text { ద் }\end{array}$ & 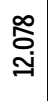 & $\stackrel{\mathscr{f}}{-}$ & $\underset{\mathbb{N}}{\mathbb{N}}$ & $\stackrel{\mathscr{m}}{\stackrel{\mathscr{I}}{-}}$ & 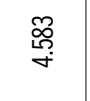 & 完 & $\begin{array}{l}\text { 岕 } \\
\text { సं }\end{array}$ & $\underset{\sim}{\stackrel{\circ}{\sim}}$ & 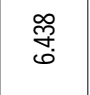 & 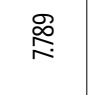 & 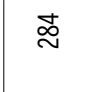 \\
\hline & ङ & $\underset{\text { กิ }}{\widetilde{N}}$ & 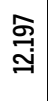 & $\underset{\sim}{\widetilde{\Xi}}$ & $\underset{్}{\mathscr{O}}$ & $\stackrel{\infty}{\stackrel{\infty}{\Im}}$ & 芯 & $\stackrel{\infty}{\stackrel{\sim}{\sim}}$ & 홍 & 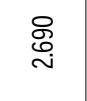 & 胥 & 㤎 & 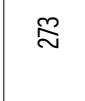 \\
\hline & \& & $\begin{array}{l}\text { ్ㅗㅇ } \\
\text { \&্ণ }\end{array}$ & ホ̃ & 迥 & 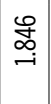 & 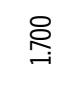 & $\stackrel{\vec{\sim}}{\stackrel{\sim}{+}}$ & 음 & 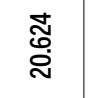 & $\underset{\sim}{\stackrel{O}{0}}$ & $\underset{\sim}{\stackrel{\sim}{\sim}}$ & ్ㅜㅇ & $g$ \\
\hline & 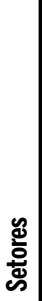 & 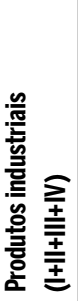 & 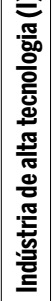 & 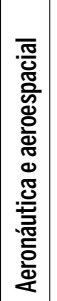 & 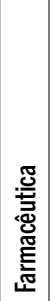 & 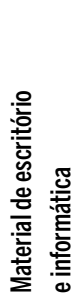 & 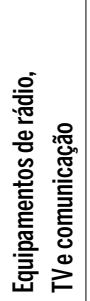 & 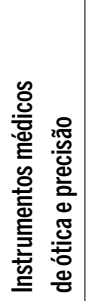 & 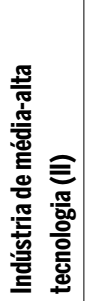 & 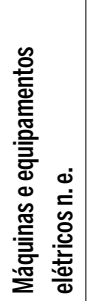 & 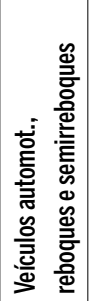 & 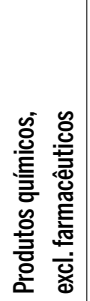 & 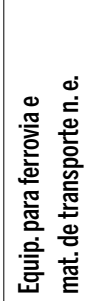 \\
\hline
\end{tabular}




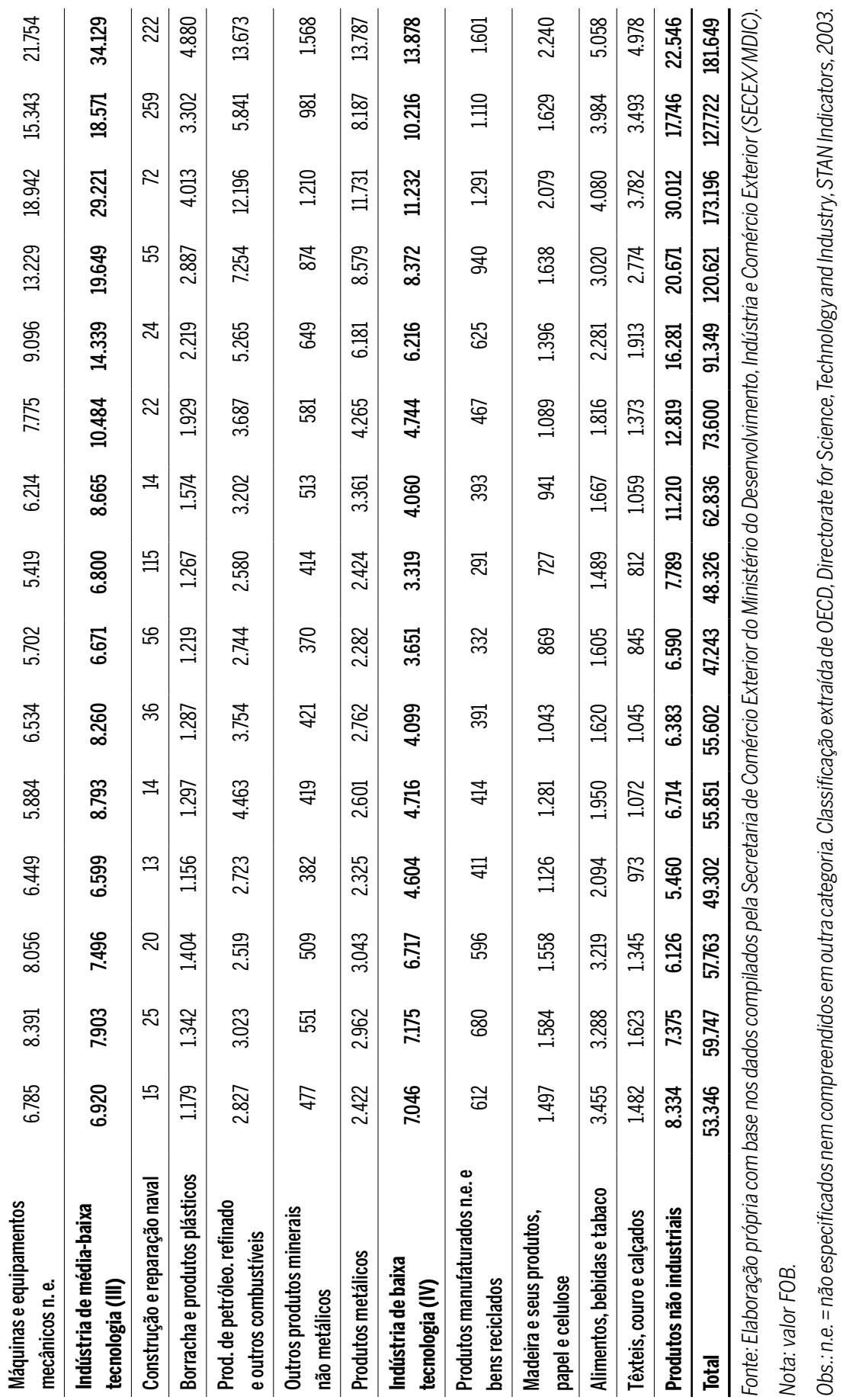

